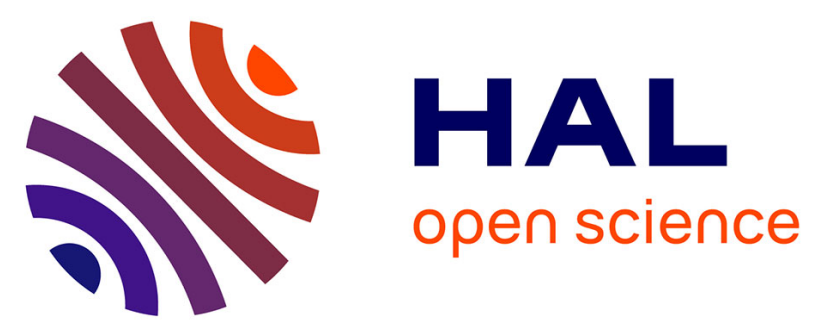

\title{
Effective elastic thickness and crustal thickness variations in west central Africa inferred from gravity data
}

Y. H. Poudjodmj Oma, J. M. Nnange, M Diament, C.J. Ebinger, J D Fairhead

\section{- To cite this version:}

Y. H. Poudjodmj Oma, J. M. Nnange, M Diament, C.J. Ebinger, J D Fairhead. Effective elastic thickness and crustal thickness variations in west central Africa inferred from gravity data. Journal of Geophysical Research: Solid Earth, 1995, vol.100 (B11), pp.22047-22070. 10.1029/95JB01149 . insu-01356057

\section{HAL Id: insu-01356057 https://hal-insu.archives-ouvertes.fr/insu-01356057}

Submitted on 24 Aug 2016

HAL is a multi-disciplinary open access archive for the deposit and dissemination of scientific research documents, whether they are published or not. The documents may come from teaching and research institutions in France or abroad, or from public or private research centers.
L'archive ouverte pluridisciplinaire HAL, est destinée au dépôt et à la diffusion de documents scientifiques de niveau recherche, publiés ou non, émanant des établissements d'enseignement et de recherche français ou étrangers, des laboratoires publics ou privés. 


\title{
Effective elastic thickness and crustal thickness variations in west central Africa inferred from gravity data
}

\author{
Y. H. Poudjom Djomani, ${ }^{1,2}$ J. M. Nnange, ${ }^{2,3}$ M. Diament, ${ }^{1}$ C. J. Ebinger, ${ }^{2}$ \\ and J. D. Fairhead ${ }^{2}$
}

\begin{abstract}
The west central African region is characterized by various geological features: Cretaceous rifts (Benue), Tertiary domal uplift (Adamawa volcanic uplift), Tertiary-Recent volcanoes (Cameroon Volcanic Line or CVL), Tertiary sedimentary basins (Chad basins), and cratonic region (Congolese craton). In this study, we investigate the relationship between these tectonic features and the flexural rigidity of the lithosphere in Cameroon, in terms of effective elastic thickness $\left(T_{e}\right)$, by the use of the coherence function analysis. For that purpose, we use a new dataset of $\sim 32,000$ gravity and topography points from Cameroon and the adjacent countries. The $T_{e}$ contour map deduced from this study shows a good relationship between the tectonic provinces and the rigidity of the lithosphere, the minima $(14-20 \mathrm{~km})$ are beneath the active rifted and volcanic areas (Benue, CVL, and Adamawa), and the maxima $(\sim 40 \mathrm{~km})$ correspond to the Archean reworked unit in Congo. A spectral analysis of the gravity data is performed to determine the crust-mantle boundary in these tectonic provinces. The crustal thickness $\left(T_{C}\right)$ contour map shows a variation from $14 \mathrm{~km}$ to about $45 \mathrm{~km}$, consistent with other geophysical data. The lower values (14-20 km) are obtained in central Cameroon on the Adamawa uplift, and the highest values are found in southem Cameroon (Archean reworked Congolese craton). Comparing $T_{e}$ and $T_{c}$ values shows that there is generally a positive correlation between the two parameters, with an exception in Chad where this correlation is rather negative.
\end{abstract}

\section{Introduction}

Research into the origin of large igneous provinces (LIPs) worldwide has led some scientists to propose that lithospheric structural discontinuities in part control the location of oceanic plateaus and continental flood basalt provinces [e.g., Hopper et al., 1992; Anderson, 1994]. One of these LIPs, the Cameroon Volcanic Line (CVL) extends across both oceanic and continental lithosphere, but volcanism shows no age progression [e.g., Fitton and Dunlop, 1985]. The continental part of the CVL and surrounding regions can be divided into two domains: a mobile belt in the north and a cratonic belt in the south, with the seismically and volcanically active CVL lying between the two (Figure 1).

The flexural rigidity $(D)$, or equivalently, the effective elastic thickness (EET or $T_{e}$ ), describes the manner in which a plate responds to lateral density variations applied at the surface or within the plate. Studies of $T_{e}$ and its variations within the oceanic plates show that $T_{e}$ is dependent upon the thermal structure of the plate, and studies of the more complicated continental plates also show some thermal dependence, although the temperature is not the only factor that controls $T_{e}$ in continents [e.g., Burov and Diament, 1995]. Thus lateral variations in $T_{e}$ may provide information on the location and depth extent of thermal and structural

\footnotetext{
T'Laboratoire de Gravimétrie et Géodynamique, Institut de Physique du Globe, Paris.

${ }^{2}$ Department of Earth Sciences, University of Leeds, Leeds, England. ${ }^{3}$ Institut de Recherche Géologique et Minière, Yaoundé, Cameroon.
}

Copyright 1995 by the American Geophysical Union.

Paper number 95JB01149.

0148-0227/95/95JB-01149\$05.00 discontinuities within the lithosphere. The objective of our study is to investigate variations in lithospheric structure beneath west central Africa, including the continental region of the CVL, and to relate these variations to Cenozoic rifting and volcanic processes.

Gravity and topography data from continental regions provide a means of mapping out variations in crustal thickness and mechanical thickness of the lithosphere. Forsyth [1985] introduced the coherence function as a robust means of estimating $T_{e}$ in continental regions. Unlike admittance functions, the coherence method assumes that topographic relief reflects both surface and subsurface density contrasts, or loads, and exploits the relationship between the Bouguer gravity and topography as a function of the wavelength. In this study, we first estimate the thickness of the crust $\left(T_{c}\right)$ throughout west central Africa by means of the gravity power spectra [e.g., Spector and Grant, 1970]. We then use the coherence method to examine variations in $T_{e}$ throughout the study region, using existing seismic data to constrain density models.

\section{Geological Setting}

The area of investigation (Figure 1) is a part of the central African mobile belt and also includes a part of the Congolese craton. The latter was created during the Liberian cycle (2800 $\mathrm{Ma})$ and rejuvenated during the Eburnean (230 -1800 Ma). The entire area was affected by the Pan-African cycle $(600 \pm 100$ $\mathrm{Ma})$ during which important tectonic movements occurred, giving rise to megashear zones in Africa [e.g., Ngako et al., 1991]. One of these zones, oriented ENE-WSW, is called the Central African Shear Zone (CASZ) and extends over about $2000 \mathrm{~km}$ from Sudan to Cameroon [Cornacchia and Dars, 1983; Moreau et al., 1987; Ngako et al., 1991]. It is a dextral 


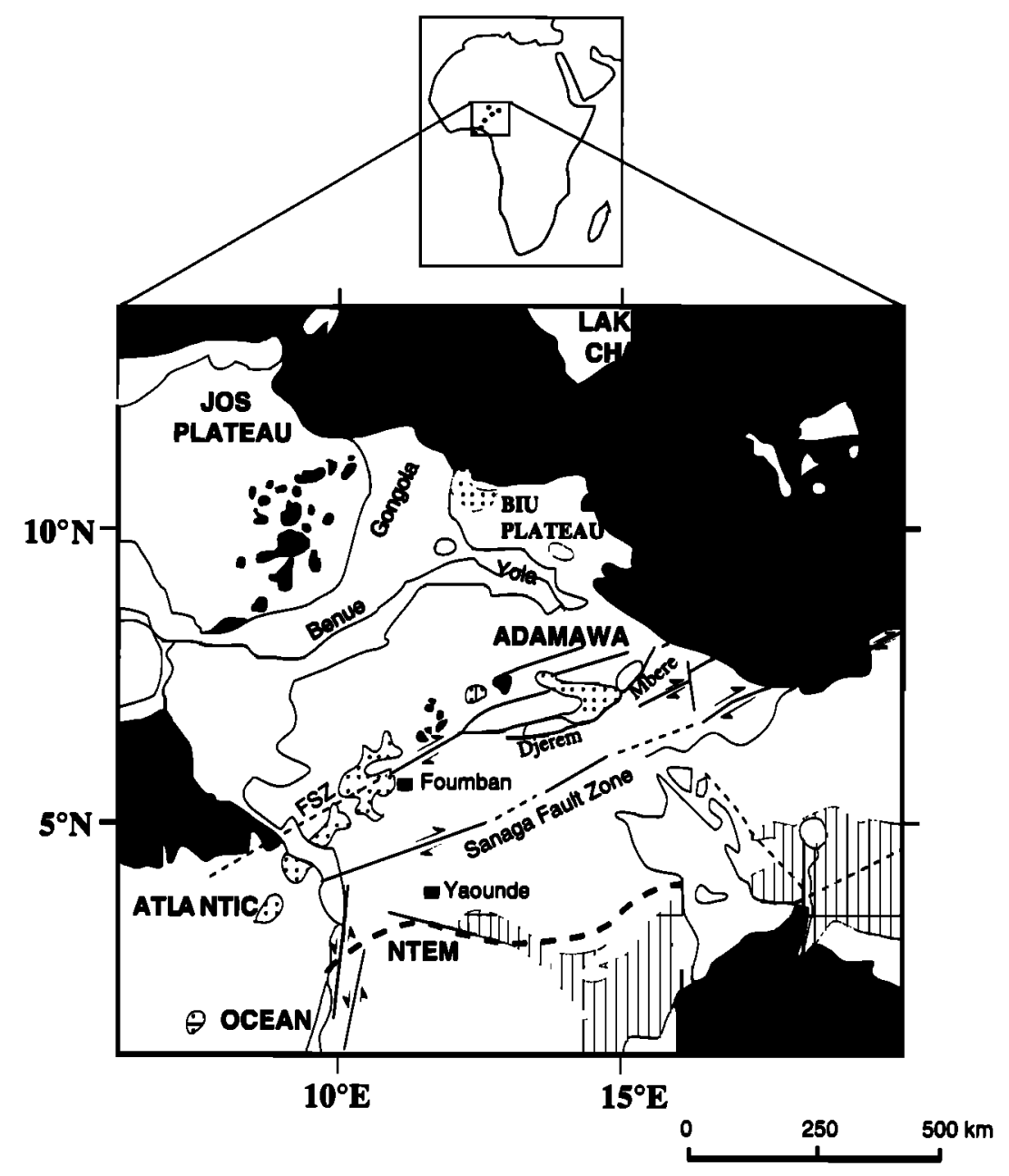

CASZ : Central African Shear Zone

FSZ: Foumban Shear Zone

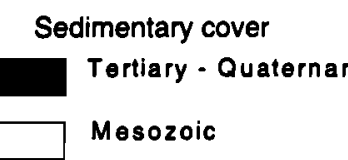

- Fault shear Zone
Basement

Proterozoic

Panafrican
Igneous rocks

$\because:::: ;$ Volcanics

Younger granites

- Northern margin of

the congolese craton

Figure 1. Geological map of the study area. The northern limit of the Congolese craton is not well known to the east of the area. Volcanic centers between Mount Oku and Biu plateau are not shown. Also shown are the Precambrian and reworked faults (e.g., CASZ, Sanaga). After Cornacchia and Dars [1983] and Sanaga fault zone from Dumont [1986].

shear zone associated with broad mylonite belts predating the opening of the South Atlantic Ocean in Cretaceous times [e.g., Jorgensen and Bosworth, 1989]. This fault extends into Brazil as the Pernambuco polycyclic lineaments [De Almeida and Black, 1967; Martin et al., 1981; Popoff, 1988]. Parallel to this fault zone and to the south of it is the Sanaga fault zone. It is also a dextral shear running from Cameroon to Central African Republic [Dumont, 1986].

The "younger granites" of the Jos plateau in Nigeria, roughly oriented along a $\mathrm{N}-\mathrm{S}$ axis, give $\mathrm{Rb}-\mathrm{Sr}$ ages between 213 and $141 \mathrm{Ma}$ [Rahaman et al., 1984; Vail, 1989]. Their origin is related either to the migration of the African plate over a mantle plume [e.g., Karche and Vachette, 1976] or shear movements along preexisting ENE-WSW trending faults in the Pan-African basement [e.g., Black et al., 1985].
The opening of the South Atlantic Ocean in Cretaceous times resulted in a series of basins and grabens in the study area, such as the Benue in Nigeria-Cameroon, the Mbere and Djerem in south Adamawa, and the Chad sedimentary basins [Benkhelil and Guiraud, 1980; Genik, 1992]. The Benue trough is a NE-SW trending basin that extends for some 900 km northeastward from the Niger delta basin on the northern end of the Gulf of Guinea to Lake Chad (Figure 1). The northeastern part consists of the Yola rift arm in Cameroon and the Gongola arm in Nigeria beneath the Chad basin. The orientation of the trough seems to be controlled by northeast trending dextral shear zones of late Pan-African age [Guiraud and Maurin, 1992]. Volcanic activity in the trough was particularly important during Cretaceous-early Tertiary times [Baudin et al., 1991; Wilson and Guiraud, 1992]. The Benue 


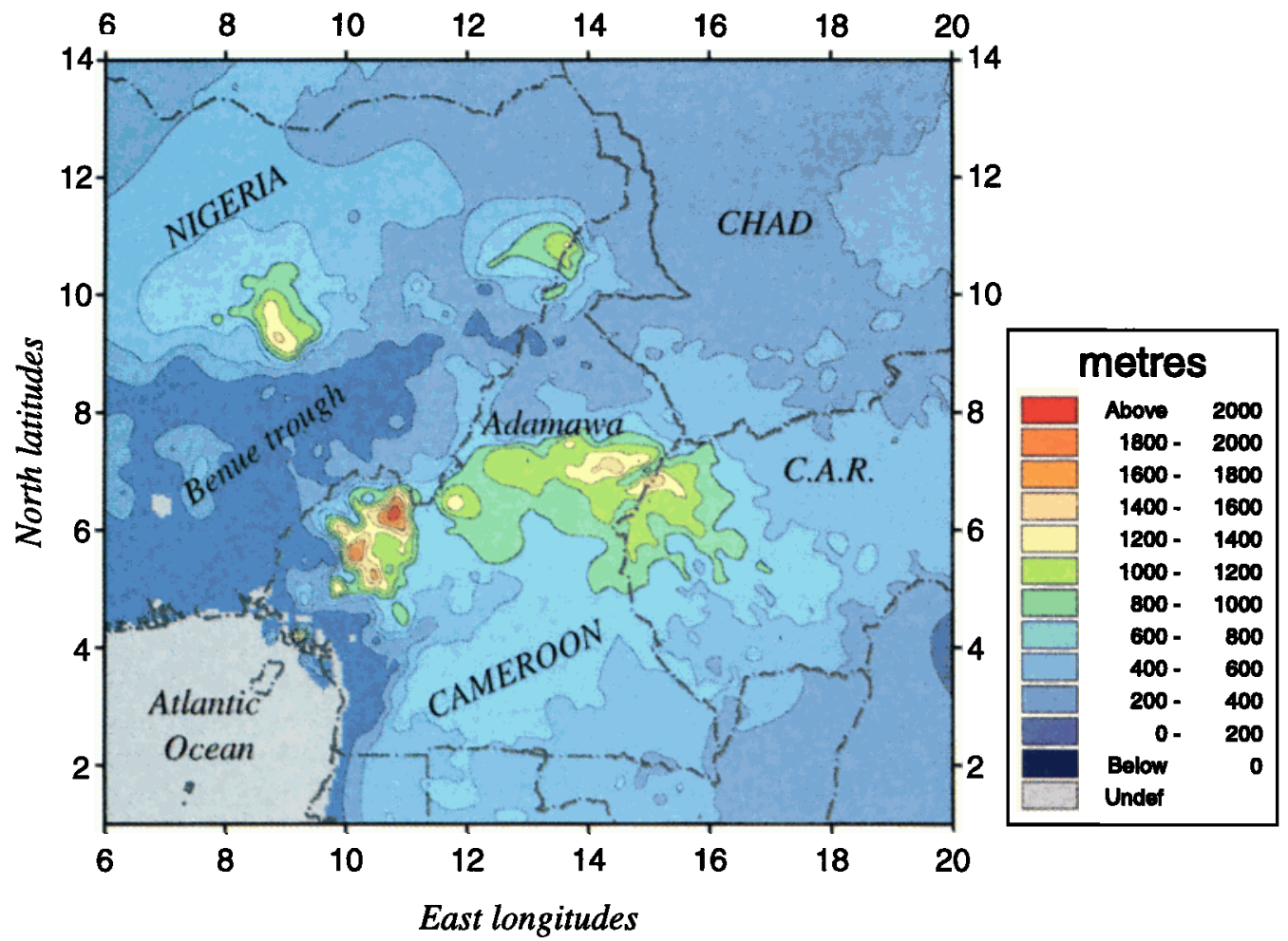

Plate 1. Topographic map of west central Africa. Note the high altitudes over the Jos, Biu and Adamawa plateaus and the volcanic centers of the Cameroon Volcanic Line oriented in a $\mathrm{N} 70^{\circ}$ to $90^{\circ}$ direction (refer to Figure 1 for location of these features). The Benue trough and the Chad sedimentary basins are characterized by altitudes less than $400 \mathrm{~m}$. CAR, Central African Republic.

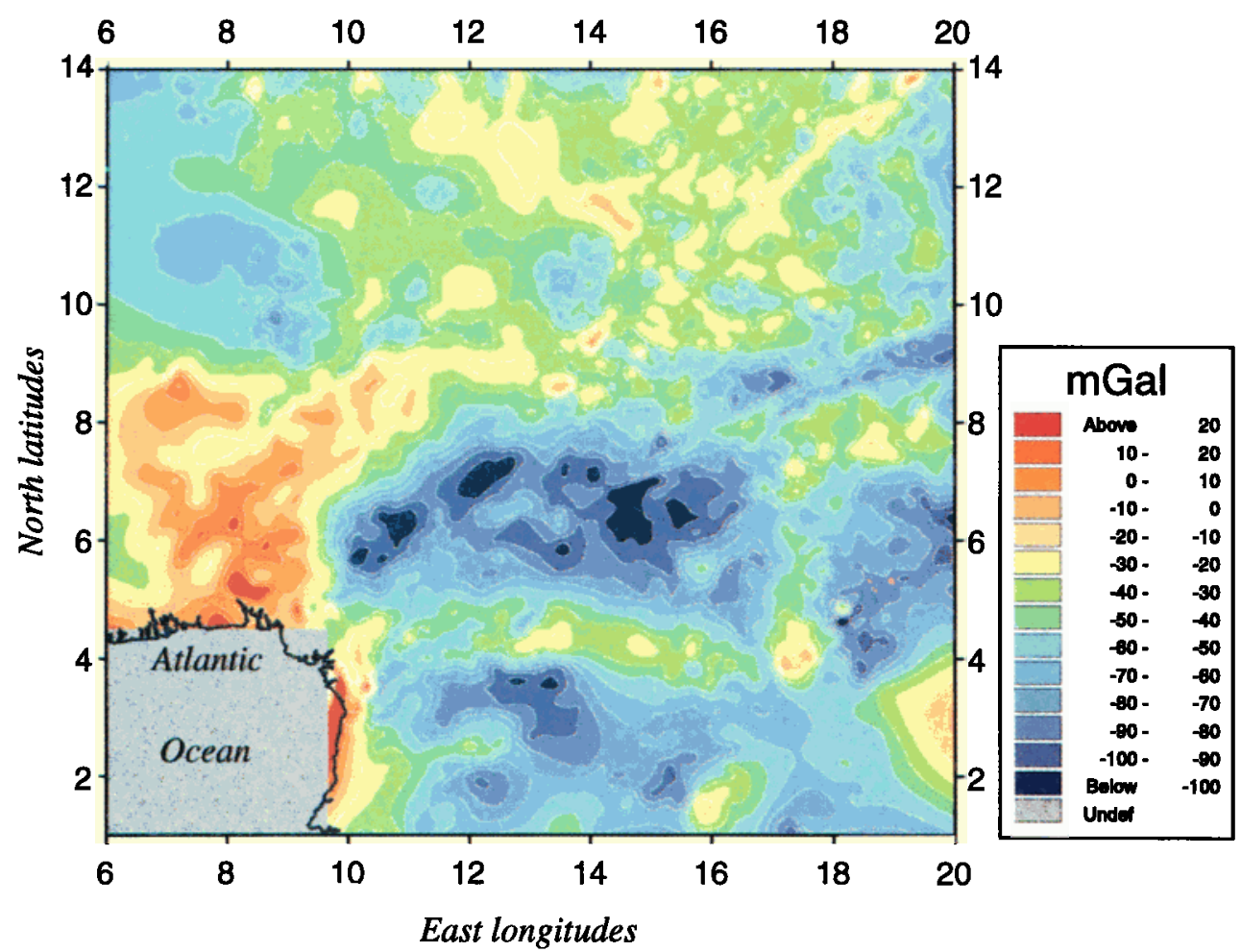

Plate 2. Bouguer anomaly map of Cameroon and the adjacent countries computed using the data in Figure 2. The map is dominated by a long-wavelength negative Bouguer anomaly in central Cameroon corresponding to the Adamawa uplift, negative anomalies on the Congolese craton, and positive anomalies on the Benue trough (refer to Figure 1 for the location of these features). 
trough is characterized by a broad positive Bouguer anomaly interpreted as crust that has been thinned and replaced by anomalous upper mantle material [e.g., Fairhead and Okereke, 1987]. The Mbere and Djerem sedimentary basins are limited to the north by the CASZ (known in Cameroon as the Foumban shear zone, or Ngaoundere rift) and characterized by conglomerates and mylonites localized along the fault zone [Ngangom, 1983]. The Chad basin is one of the African intracontinental basins in the Pan-African reactivated basement. Its origin is controversial: Burke [1976], and, recently, Genik [1992] suggest that the basin owes its origin to the existence of a number of peripheral uplifts and is underlain by deep rift systems formed in Early Cretaceous during the separation of Africa from South America. Cratchley et al. [1984] and Freeth [1984] suggest a Precambrian origin for the basin.

The area is also dominated by a series of Tertiary-Recent volcanic centers that form the CVL. This $1600-\mathrm{km}$-long line straddles the west African continental margin, and extends from the Atlantic Ocean to the Biu plateau in northern Nigeria
(Figure 1). Magmatic activity has occurred on the line from 65 Ma to Present and shows no age progression [Fitton and Dunlop, 1985]. A part of the line runs eastward toward the Adamawa volcanic uplift in central Cameroon (Figure 1). Thus the line seems to be superimposed on the preexisting CASZ which cuts across the Adamawa uplift [e.g., Moreau et al., 1987; Déruelle et al., 1991; Wilson and Guiraud, 1992]. Seismological studies revealed low upper mantle velocities, interpreted as an abnormally hot upper mantle beneath the Adamawa uplift, and a lithospheric thinning [Dorbath et al., 1986; Plomerova et al., 1993]. Several earthquakes have been registered in the area within the last 5 years, with magnitudes up to 4.8. Seismological studies show that this recent seismic activity is related to the magmatic activity of the line [Tabod et al., 1992].

The topographic map of the study area correlates well with the tectonic provinces (Plate 1). The $130-\mathrm{km}$-wide Jos plateau is characterized by elevations above $800 \mathrm{~m}$. Also elevated is the 700-m-high Biu plateau. The highest elevations occur in southwest Cameroon and correspond to the volcanic centers of

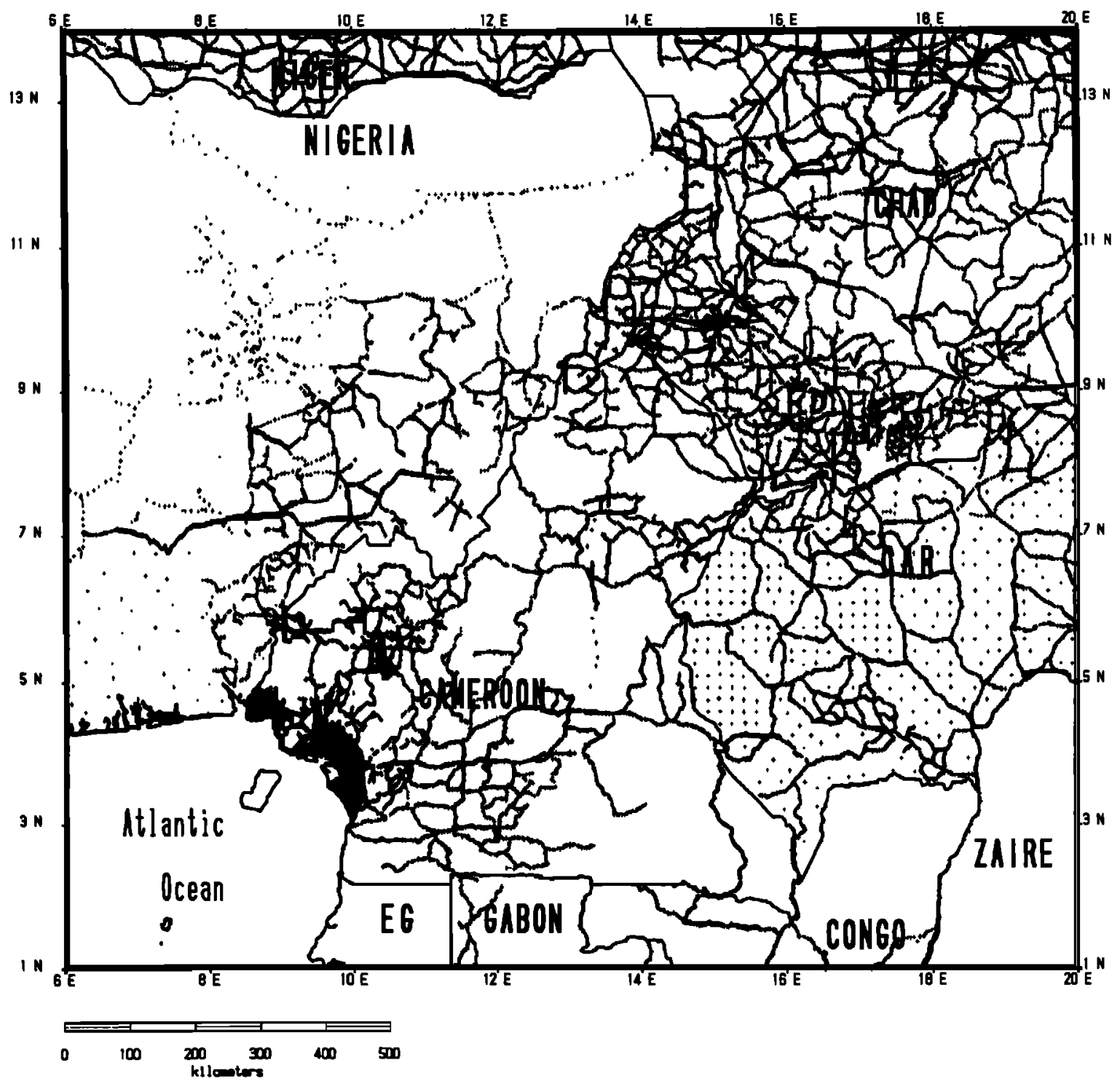

Figure 2. Gravity data distribution in Cameroon and adjacent countries. EG, Equatorial Guinea. See text for the sources of these data. 


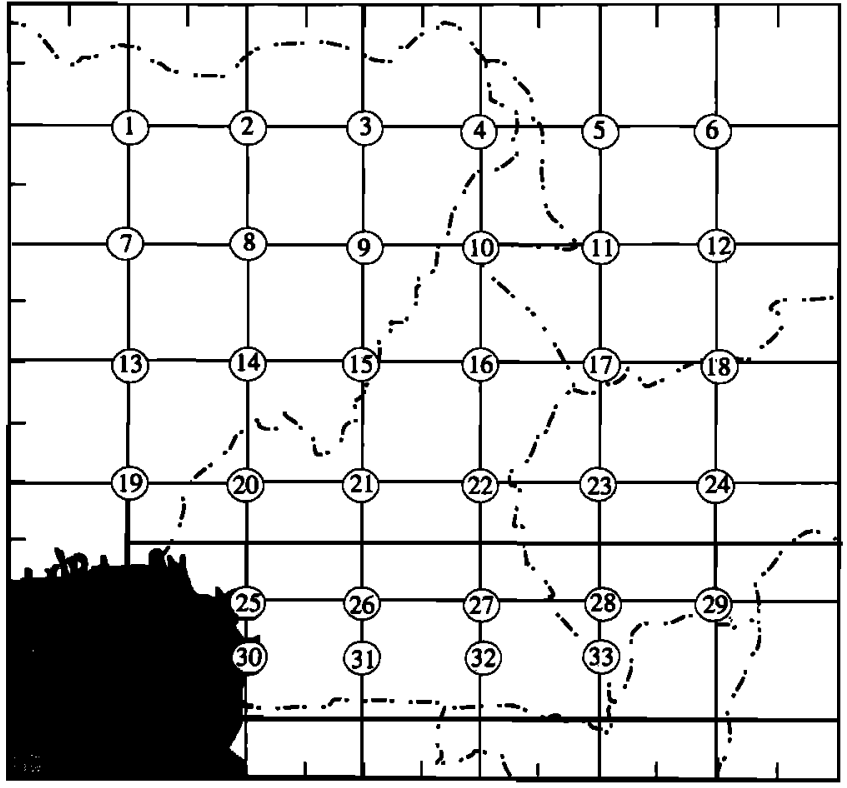

-. .-. Political boundary

Figure 3. The 33 grids used for the estimation of $T_{e}$, as well as for the Moho depth. Note that the grids are overlapping on each other. All the grids are numbered in their center.

the CVL. In this area, Mount Cameroon, the only active volcano of the line, rises to $4095 \mathrm{~m}$. The Cretaceous Benue trough is characterized by altitudes less than $200 \mathrm{~m}$, and steep topographic gradients on the flanks, whereas the Tertiary sedimentary basins in Chad are at altitudes between $300 \mathrm{~m}$ and $500 \mathrm{~m}$. The Congolese craton is characterized by altitudes between $500 \mathrm{~m}$ and $800 \mathrm{~m}$. The study area thus encompasses several geological features, of different ages, length scales, and elevations, suggesting different modes of isostatic compensation and/or lithospheric structure.

\section{Data and Grids}

The data used in this study were acquired during several surveys carried out in Cameroon and adjacent countries by (1) ORSTOM (Institut Français de la Recherche Scientifique pour le Développement en Cooperation, France) between 1960 and 1967, (2) J. D. Fairhead in 1982, (3) Nnange [1991] at IRGM (Institute of Geological and Mining Research, Cameroon) and University of Leeds (England), (4) DMA (U.S. Defense Mapping Agency), and (5) ELF Aquitaine oil company (unpublished). These data sets consist of approximately 32,000 irregularly spaced elevation points and corresponding gravitational acceleration values determined from both land and air surveys (Figure 2). Where height information was available, Hammer's [1939] method was used for terrain corrections on the data [Nnange, 1991]. All the data were tied to the IGSN71 reference system. A density reduction of 2670 $\mathrm{kg} / \mathrm{m}^{3}$ was used for the Bouguer correction. Latitudes and longitudes were converted to $(x, y)$ coordinates using a UTM projection and a central meridian at longitude $13^{\circ} \mathrm{E}$. Data were then interpolated to a $18.5-\mathrm{km}$-spacing grid using a finite element algorithm [Inoue, 1986; El Abbass et al., 1990]. The total grid has $85 \times 79$ points (in the $x$ and $y$ directions, respectively), which means $1554 \mathrm{~km} \times 1443 \mathrm{~km}$. The same transformations were applied to the gravity and topographic data. From the total grid, we extracted 33 subgrids of gravity and corresponding topography, each $444 \mathrm{~km} \times 444 \mathrm{~km}$ (25 x 25 points). These subgrids (Figure 3 ) were used to perform source depth estimations by spectral analysis of the gravity data and also to estimate the effective elastic thickness $\left(T_{e}\right)$ of the lithosphere.

We computed the two-dimensional (2-D) Fourier transform of the data on each subgrid using the algorithm of Singleton [1969]. This allowed us to obtain the spectral amplitudes of Bouguer gravity and topography. Prior to this transformation, the gridded data were mirrored about their eastern and southern boundaries in order to avoid edge effects. This produced data sets twice the original length and width. The longest wavelengths in the Fourier transform exceed the initial dimensions of the grids, due to mirroring, and were rejected before the inversion for $T_{e}$.

Plate 2 is a new Bouguer anomaly map of Cameroon and adjacent countries. This map clearly shows the long wavelength negative Bouguer anomaly of about $-120 \mathrm{mGal}$ centered on the Adamawa massif in central Cameroon. This anomaly is oriented NE-SW near the coast following the volcanic massifs of the CVL, and it becomes E-W in the Adamawa region. The long-wavelength negative Bouguer anomaly beneath the Adamawa uplift can be compared to the anomalies of other African uplifts (Hoggar, Air, Darfur, and Tibesti and the Kenya dome) and is commonly interpreted as due to a low-density body in the upper mantle [Browne and Fairhead, 1983; Okereke, 1988].

Located at the western margin of the CVL, the Benue trough is characterized by NE-SW relative positive anomalies of amplitude $40 \mathrm{mGal}$. These anomalies could be compared to those of other active rift zones in east Africa. The anomalies northwestward of the trough are to be interpreted with care because of a lack of data in this area. The SW-NE positive anomalies observed in Chad correlate with either the sedimentary basins and grabens that initiated during Cretaceous times [Genik, 1992] or a basic intrusion into the basement beneath shallow sedimentary cover, which could represent a suture zone [e.g., Freeth, 1984]. We can also note the negative anomalies of the CASZ in central Africa, in a ENE-WSW trend.

Southern Cameroon is characterized by negative anomalies (-80 $\mathrm{mGal}$ ) which correspond to the northern part of the Congolese craton. The limit of this craton is marked by a low and regular vertical gradient of about $1 \mathrm{mGal} / \mathrm{km}$, which marks a change in density of crustal rocks from the north to the south [Collignon, 1968]. On the gravity map, it is shown as E-W positive anomalies between the negative anomalies to the north (Adamawa uplift) and to the south (Congolese craton). In the next sections, we use these gravity anomalies to constrain the crustal structure and the mechanical lithospheric thickness beneath the CVL and west central Africa to investigate the possible control of the lithosphere on the location of the CVL.

\section{Structure of the Crust}

In this part of the study, we use the 33 sub $_{z}$ ds of Figure 3 to estimate the crustal thickness $\left(T_{C}\right)$ and its variations within 
the study area, by spectral analysis of the gravity data. The same subgrids for $T_{e}$ estimations will be used in the second section of the paper.

\section{Method}

Spector and Grant [1970] described a statistical method to determine average depths of various magnetic layers by considering the random distribution of sources. This is achieved by a plot of the logarithm of the power of the magnetic anomalies versus the wavenumber. This method was improved and adapted for gravity data by Syberg [1972].

Given a grid of data and its corresponding 2-D Fourier transform, the 2-D power spectrum is calculated by the relation

$$
S\left(k_{x}, k_{y}\right)=X_{R}\left(k_{x}, k_{y}\right)^{2}+X_{I}\left(k_{x}, k_{y}\right)^{2}
$$

where $X_{R}\left(k_{x}, k_{y}\right)$ and $X_{I}\left(k_{x}, k_{y}\right)$ are the real and imaginary parts, respectively, of the data at the point $\left(k_{x}, k_{y}\right)$. After this, the radial spectrum is computed by averaging the power spectrum in concentric rings of constant $|k|$, where $|k|=\left(k_{x}{ }^{2}+\right.$ $\left.k_{y}{ }^{2}\right)^{1 / 2}=2 \pi / \lambda$ and $\lambda$ is the wavelength. So, if $k$ denotes the wavenumber and $S(k)$ denotes the power spectrum, the depth to the body $(h)$ can be estimated by

$$
h=-\operatorname{Ln}[S(k)] / 2|k|
$$

If we plot the logarithm of the power spectrum versus the wavenumber, some straight-line segments can be identified, the slopes of which are proportional to the depth to the top of the buried body [e.g., Pal et al., 1979; Chakraborty and Argawal, 1992; Poudjom Djomani et al., 1992]. This depth is estimated by a least squares fitting of the linear segments on the data points.

\section{Error Estimations on $T_{c}$}

While computing the power or radial spectrum for source depth estimations, errors due to three important points must be considered: the window size, the data spacing, and the selection of the linear segments on the plots [Dimitriadis et al., 1987]. Regan and Hinze [1976] show that for gravity fields, a window size of 6 times the source depth is required for less than $10 \%$ information loss. In our case, each grid is 444 km x $444 \mathrm{~km}$, and we limit depth estimates to $74 \mathrm{~km}$. Grid spacing also affects the depth estimation. According to Cianciara and Marcak [1976], the shallowest depth estimate from a power spectrum must be at least $40 \%$ of the grid spacing interval. Since our grid spacing is approximately $18.5 \mathrm{~km}$, this equates to shallowest estimated depth of $7.4 \mathrm{~km}$. The third source of error relates to the choice of the regression lines. In general, more than one linear segment can be seen on the plots; the high frequency components indicate noise effects, the low frequencies indicate the regional effects, and the intermediate frequencies represent the target sources. In this study, we present and discuss only the results corresponding to the depth to the crust-mantle boundary. In order to choose the proper wave band for this depth, we use seismic refraction constraints. That is, on the spectrum corresponding to the only region where some seismic refraction results are available (in the Adamawa region), first, we define several possible linear segments and estimate the corresponding depths (Figure 4, grid 21). Then we select the wavenumber band that gives a depth closest to the Moho determined from seismic data, i.e., $23 \mathrm{~km}$ [Stuart et al., 1985]. This wave band is between $0.06 \mathrm{~km}^{-1}$ and $0.12 \mathrm{~km}^{-1}$ (Figure 4). Note that a slight variation of the limits of the waveband gives rise to an error on the depth between 2 and $4 \mathrm{~km}$. Since all the 33 subgrids are the same size, we finally obtain $T_{c}$ values from the slopes of the straight lines of the 32 spectra in this selected wave band. However, according to the shape of each spectrum, we slightly vary the selected wavenumber band, such as to choose the group of data points which best fits a linear segment near the predefined wavenumber range (see, for example, grids 16 and 22 on Figure 4). The errors in the depth estimates are thus due to the quality of the linear fit and to the choice of the wave band (Figure 4). They vary from 1 to $10 \mathrm{~km}$ (Figure 5 and Table 1).

\section{$T_{c}$ Map and Interpretation}

The values of Table 1 were interpolated to compute a map of $T_{c}$ variation within the area (Figure 6). $T_{c}$ varies from 14 $\mathrm{km}$ in the NE of the map to $45 \mathrm{~km}$ in the south. Also evident on the map is a thinning of the crust along an E-W trend in central Cameroon, beneath the Adamawa uplift. Some clear trends are visible if we subdivide the area into four blocks: the northeastern, central, transition, and southern blocks.

Northeastern block (grids 5 and 6). This block correlates with the poorly understood region in Chad where little subsurface information exists (Figure 1). The regression line is well defined on both plots, and the corresponding depths $(13.6 \pm 2 \mathrm{~km}$ and $14.6 \pm 1 \mathrm{~km}$ for grids 5 and 6 , respectively) are the lowest values obtained in the study area. The Chad region has good data coverage, and the size of the box was shown, in the previous section, to be sufficient for the estimation of depths up to $74 \mathrm{~km}$. However, we enlarged the box to $555 \mathrm{~km} \mathrm{x} 666 \mathrm{~km}$ and obtained a depth of about 15 $\mathrm{km}$. So, our result here is well constrained. The thickness of a normal cratonic crust is commonly more than $30 \mathrm{~km}$ [e.g., Mourgues, 1983; Soller et al., 1982; Hadiouche and Jobert, 1988]. Thus it seems that in this area, the crust-mantle boundary is masked by a more pronounced intracrustal density contrast which is determined here. This area needs to be investigated by additional geophysical methods to confirm our results.

Central block (grids 15 to 24). This region corresponds to the Adamawa uplift in central Cameroon. The average crustal thickness determined here is between 18 and 23 $\mathrm{km}$. In order to test the reliability of our result in this area, we selected a larger box, $444 \mathrm{~km} \times 888 \mathrm{~km}$. The slope of the regression line in the selected wave band gives an estimate of $23 \pm 2 \mathrm{~km}$ for the average crustal thickness. These results show that the crust is thinned in this area relative to the surrounding, in agreement with seismic refraction studies which show that $T_{c}$ varies from $23 \mathrm{~km}$ in the north of the Adamawa uplift to $33 \mathrm{~km}$ in the south [Stuart et al., 1985]. On the other hand, petrologic studies carried out on mantle xenoliths suggest that the crust-mantle boundary beneath the Adamawa uplift is not deeper than $25 \mathrm{~km}$ [Girod et al., 1984]. The main result here is that the central block (Adamawa uplift) is characterized by a thinning of the crust.

Transition block (grids $7,8,9,10,11,13,14$, and 19). This corresponds to all the areas where the crustal 
Grid 16

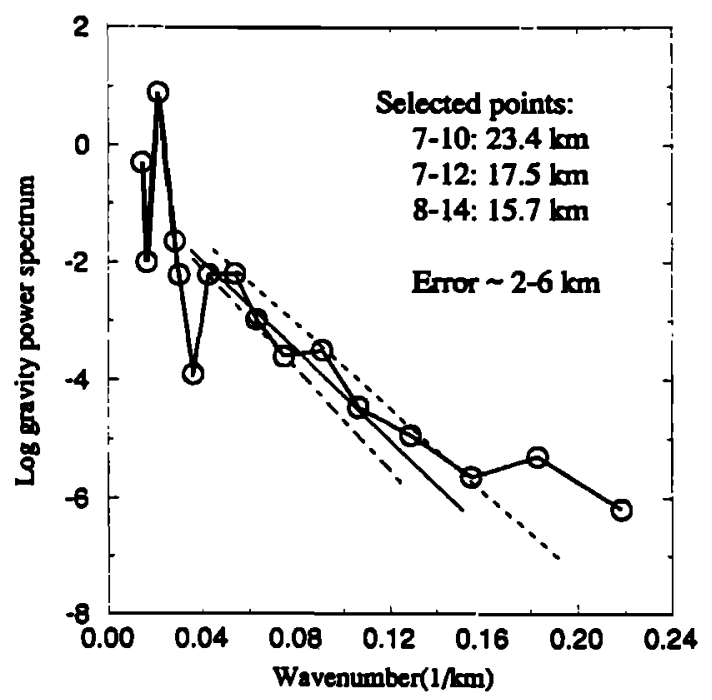

Grid 21

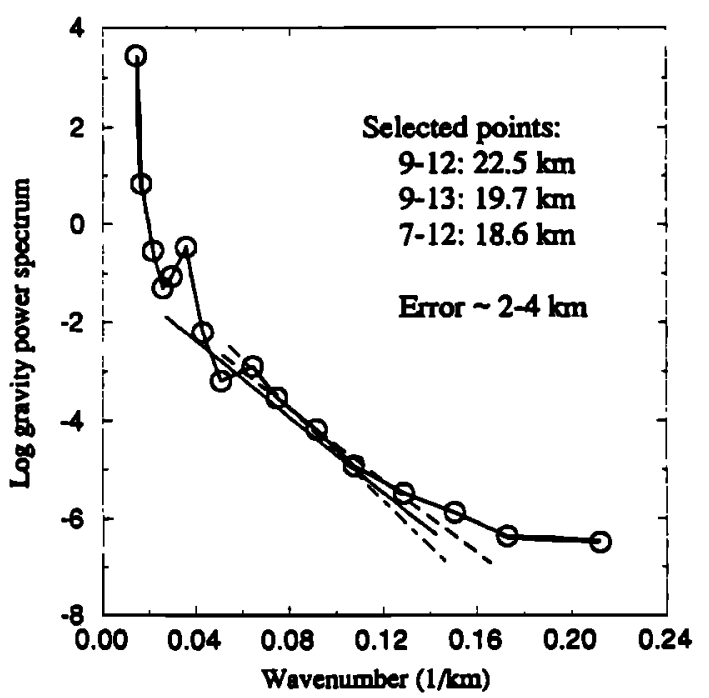

\section{Grid 22}

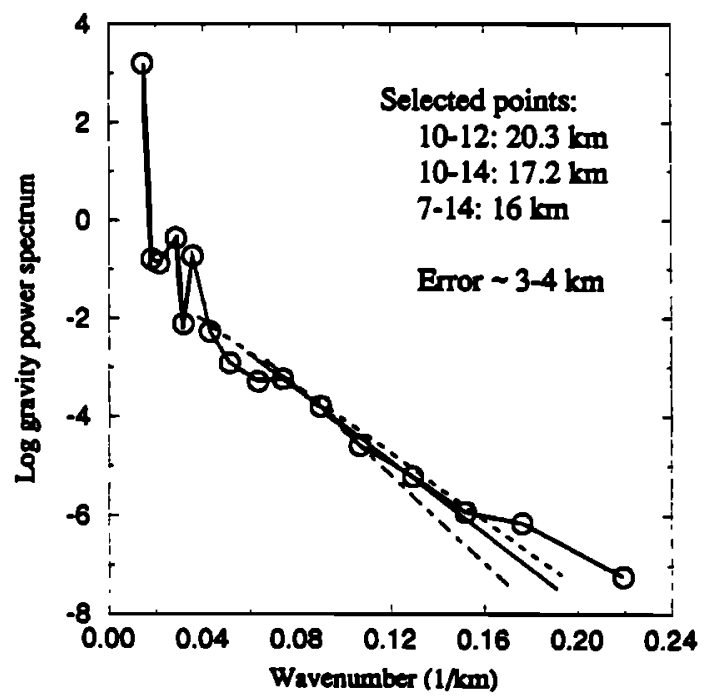

Figure 4. Selection of the wave bands for the estimation of the average crust-mantle boundary and error estimations: example of grids 16, 21, and 22 corresponding to the Adamawa uplift. For each plot, the first set of points selected give the average crust-mantle boundary. The other sets of points are selected to show the possible variation of the limits of the wavenumber band and the corresponding errors on the depth.

thickness varies from 24 to $33 \mathrm{~km}$. These areas are localized to the north, the southeast, and south of the Adamawa uplift. To the northwest, the Jurassic Jos granitic plateau in Nigeria is characterized by a $27 \pm 5 \mathrm{~km}$ thick crust. Southward, in the Benue rift, the average crustal thickness is between 15 and 33 $\mathrm{km}$. The 15-km-thick crust belongs to the central lower Benue, while the $33 \mathrm{~km}$ thickness is for the western lower Benue. A value similar to the latter is found along the northwestern margin of the Adamawa uplift and corresponds to the Gongola rift (a branch of the Benue trough). Previous gravity studies of the Benue trough show that the amount of crustal extension is about $90 \mathrm{~km}$ perpendicular to the axis of the trough [Fairhead and Okereke, 1987, 1990]. Eastward, beneath the Yola rift, $T_{c}$ is about $25 \mathrm{~km}$. These results suggest that the crust is thinned beneath the Yola rift, north of the Adamawa uplift. Fairhead and Okereke [1987] performed a three-dimensional inversion of gravity data, taking into account the seismological constraints [Stuart et al., 1985]. This inversion reveals that the average crustal thickness is 20 , 23 and $30 \mathrm{~km}$ for the lower Benue, the Yola, and the Gongola 
Grid 1

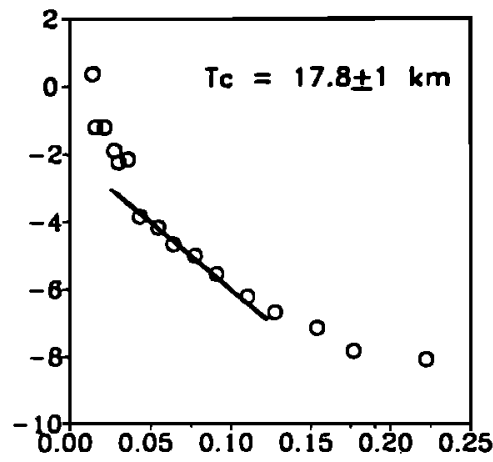

Grid3

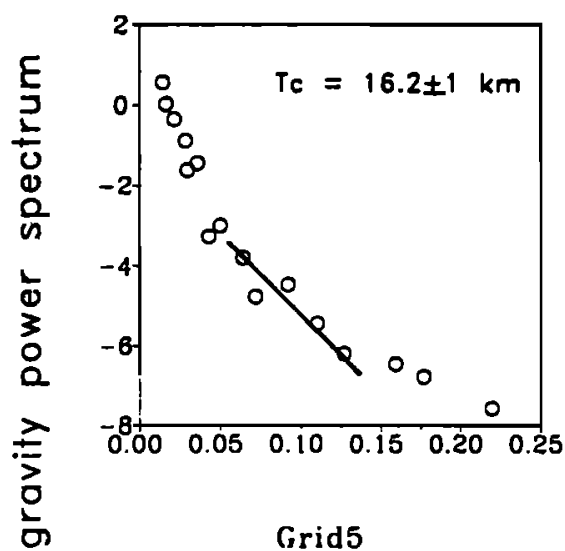

ర)

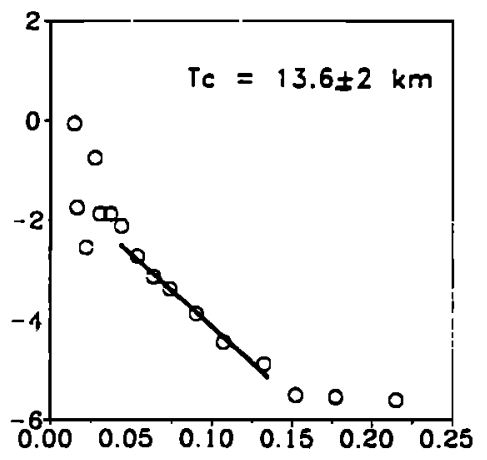

Grid7

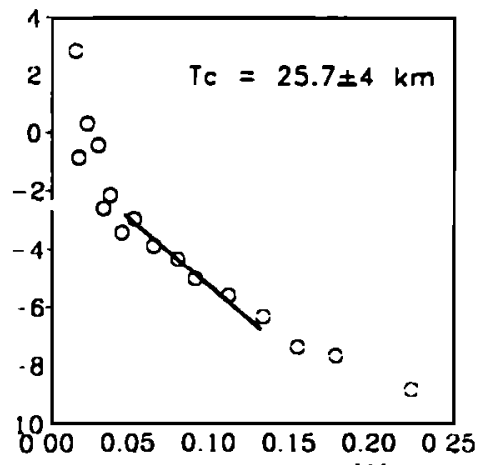

Wavenumber

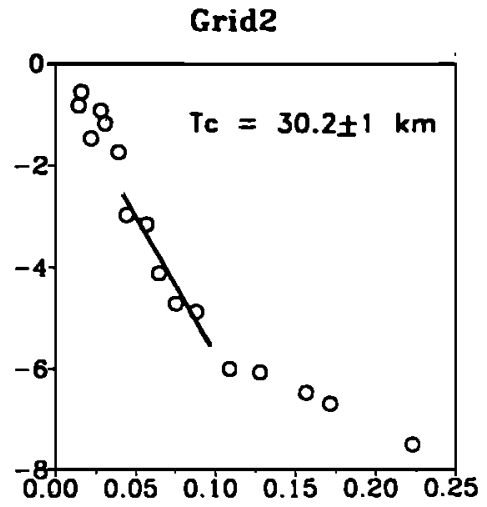

Grid4

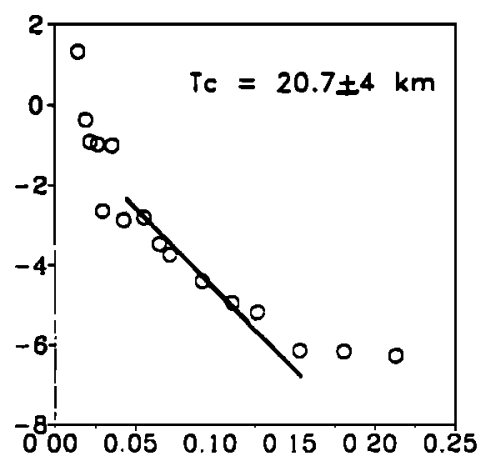

Grid6

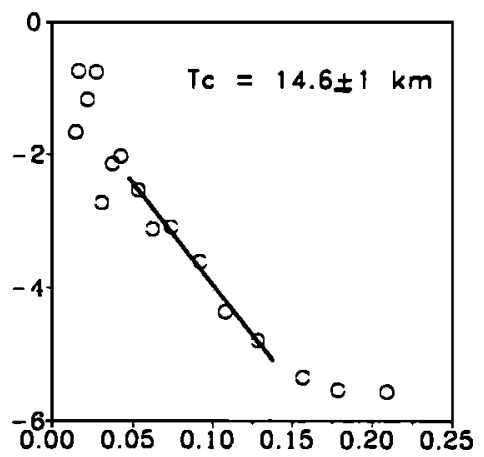

Grid8

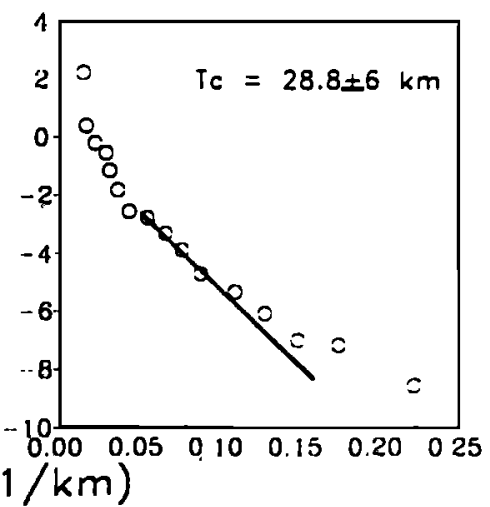

Figure 5. Plots of the logarithm of the gravity power spectrum versus the wavenumber, for the 33 grids. For each grid the slope of the selected regression line gives the value of $T_{c}$ which is indicated at the upper right corner of each plot with the corresponding error. The $T_{c}$ values are listed in Table 1. 
Grid9

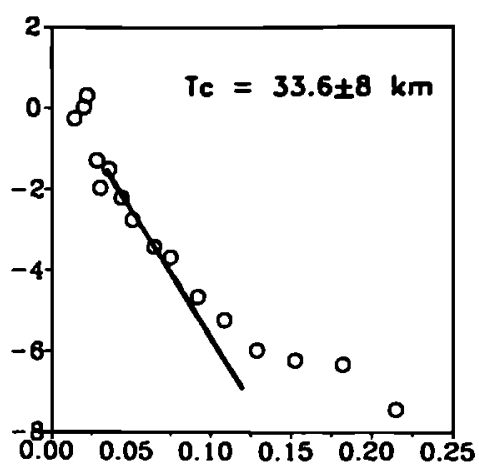

Grid11

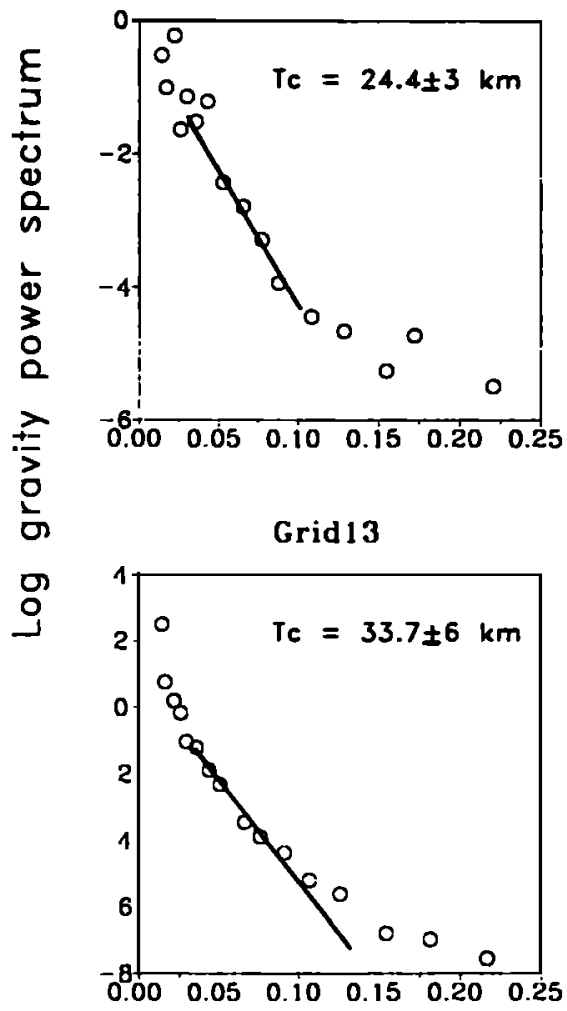

Grid 15

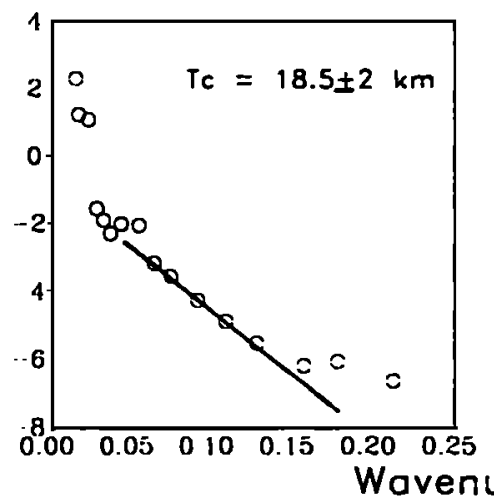

Grid 10

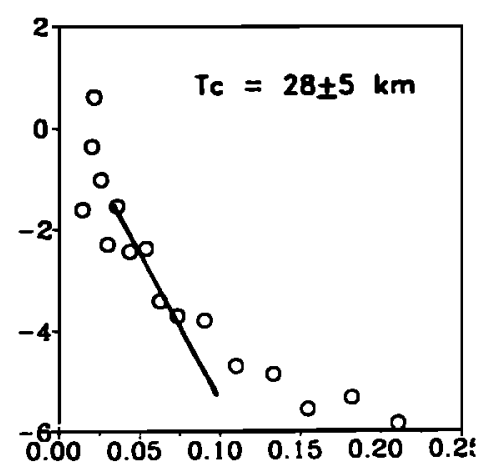

Grid 12

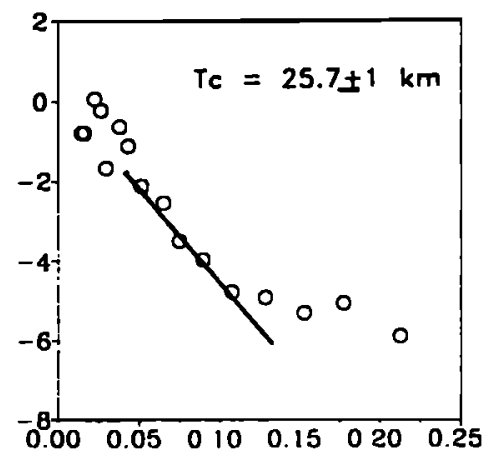

Grid 14

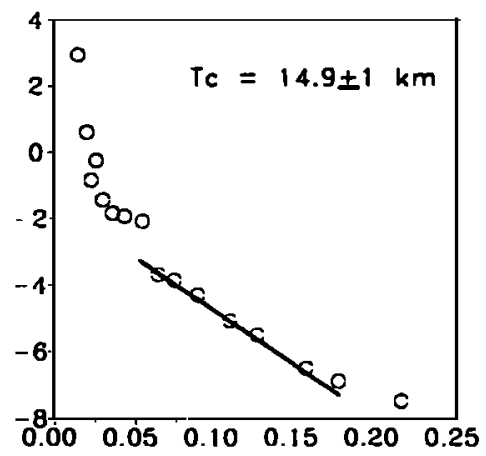

Grid 16

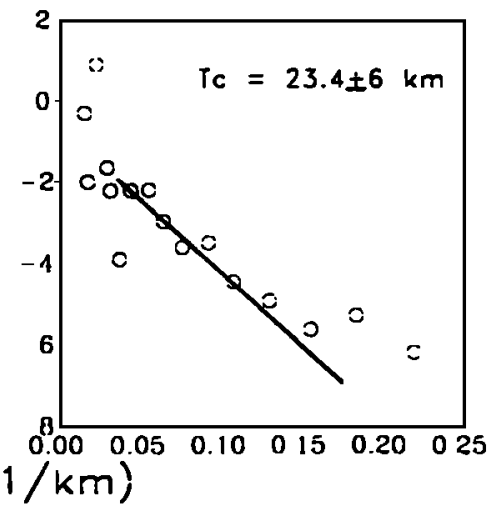

Figure 5. (continued) 


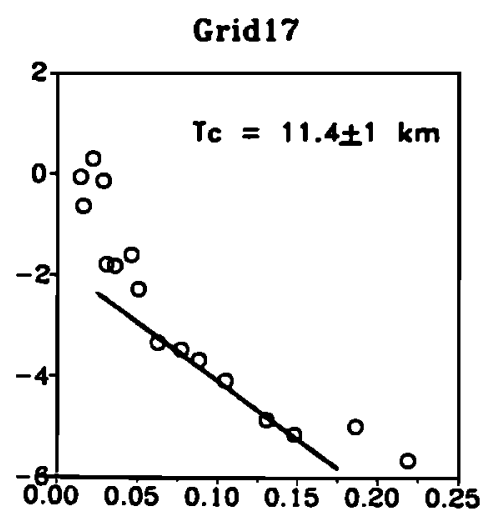

Grid18
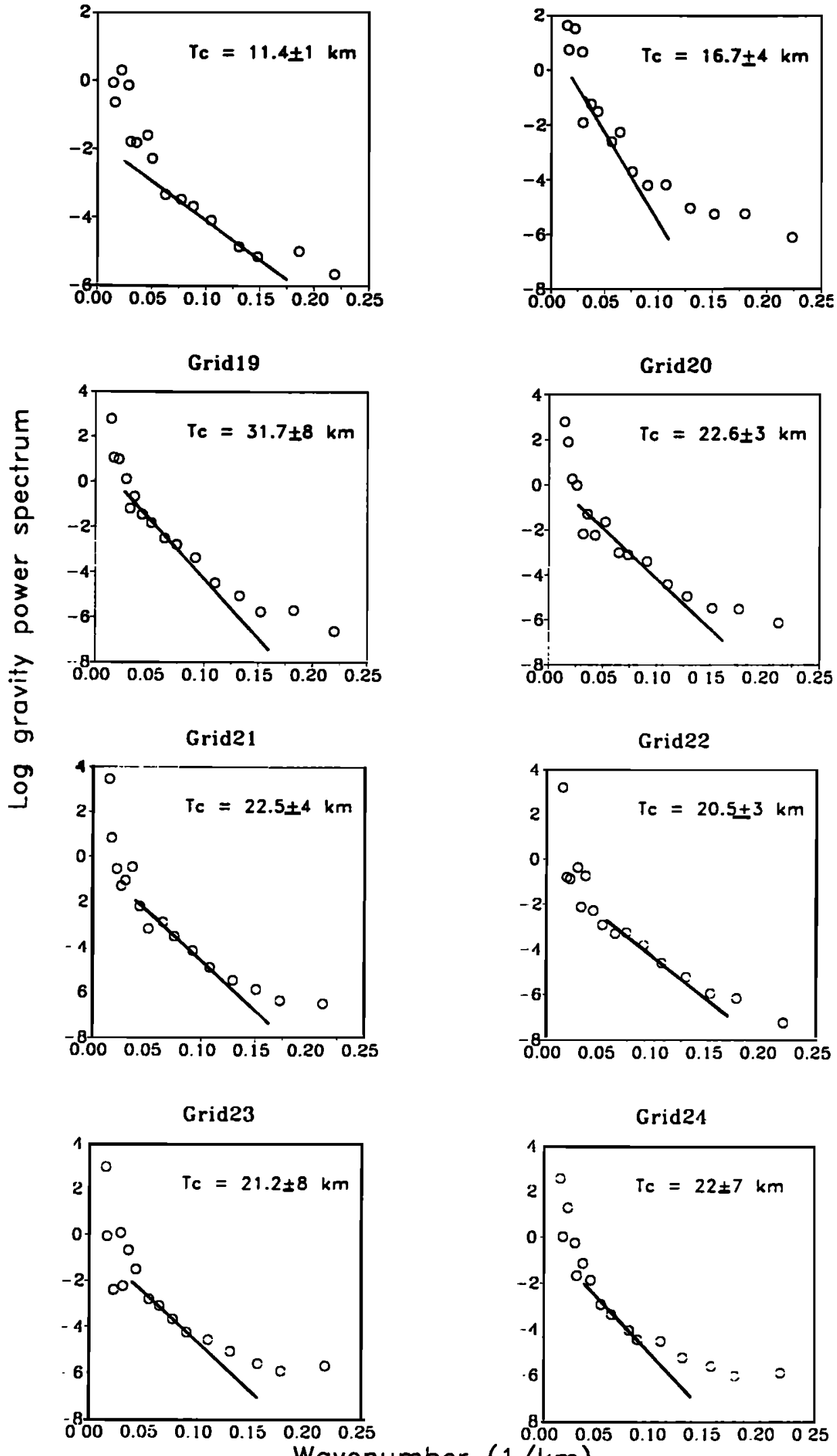

Wavenumber
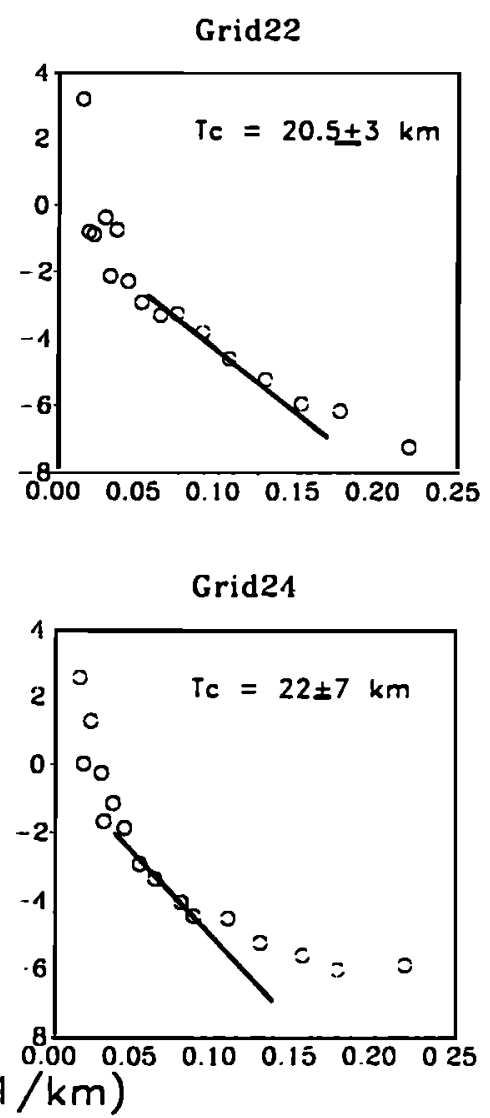

Figare 5. (continued) 
Grid25

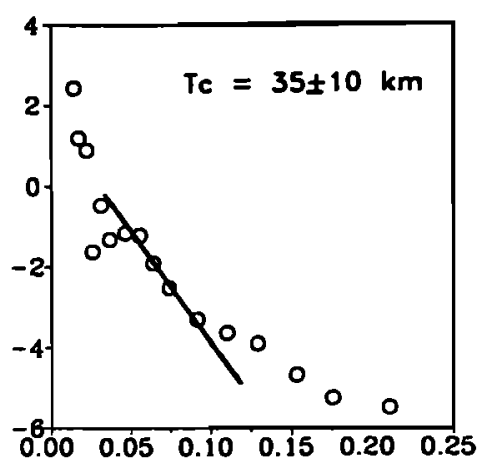

Grid27

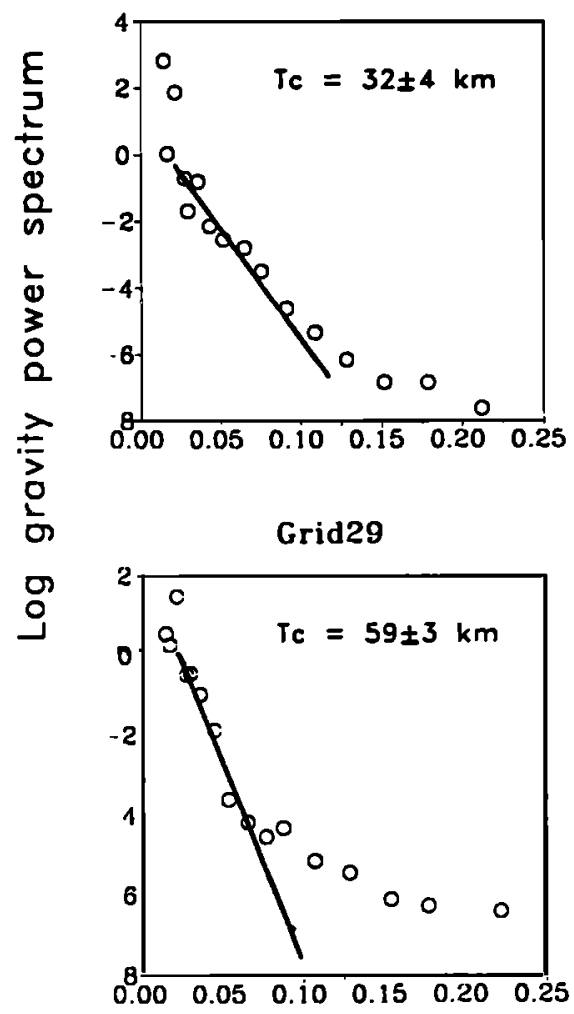

Grid31

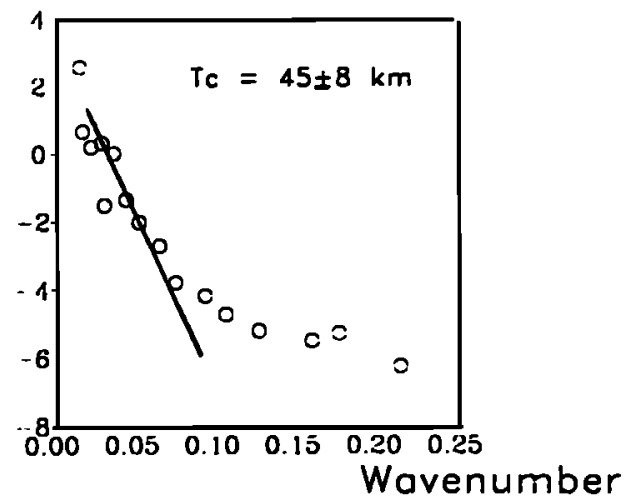

Grid26

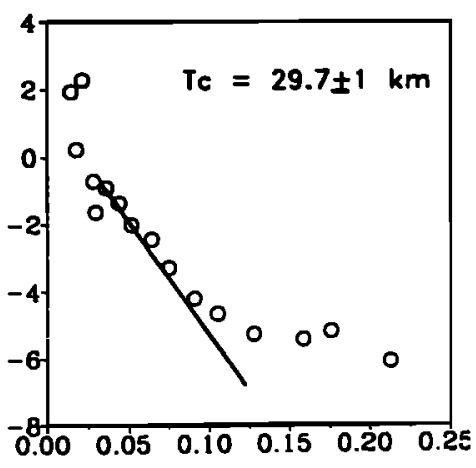

Grid28

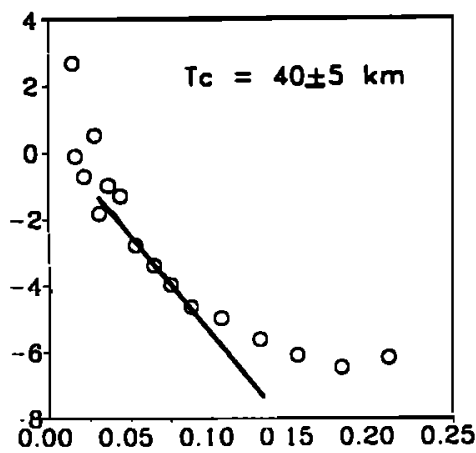

Grid30

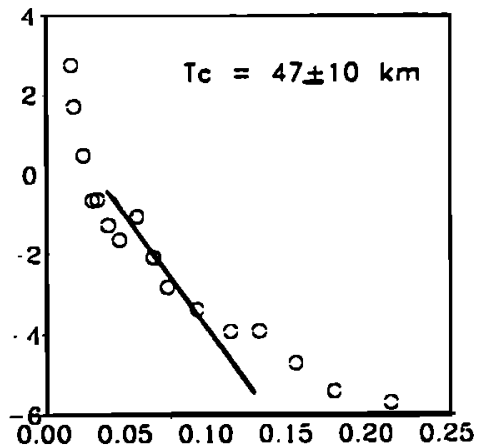

Grid32

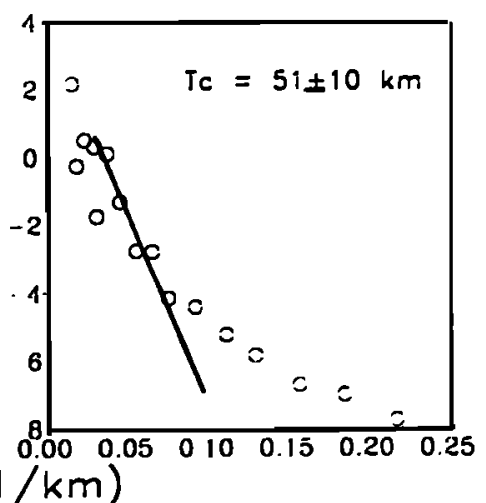

Figure 5. (continued) 


\section{Grid33}

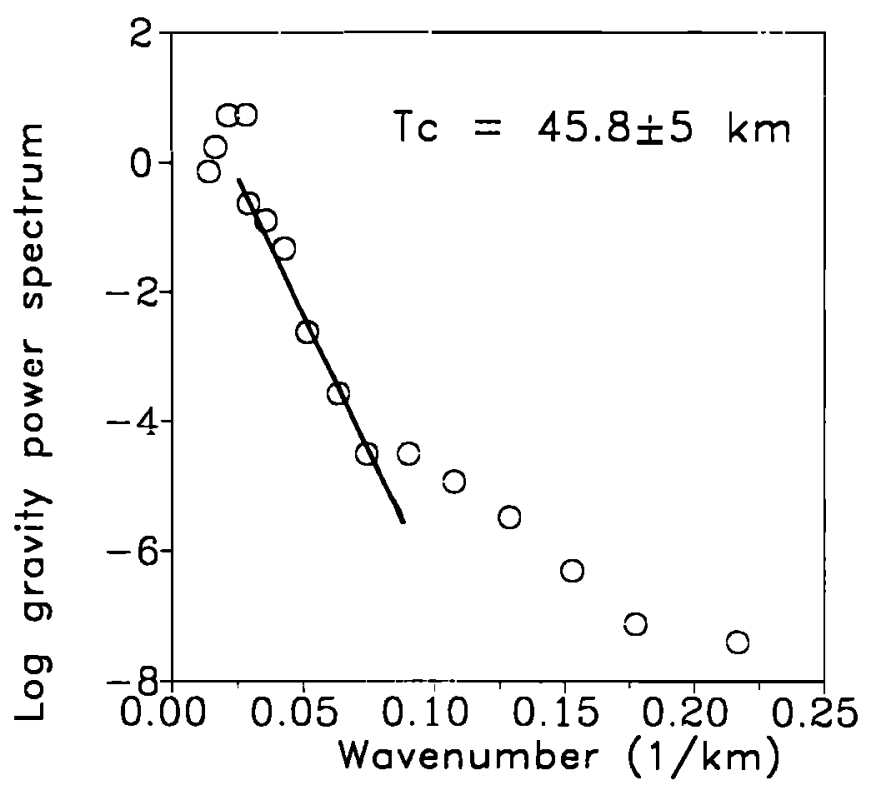

Figure 5. (continued)

rifts, respectively. According to these estimates and in the view of our results, the crust is thinner in the lower than in the upper Benue rift.

To the south of the Adamawa uplift, $T_{c}$ increases to $26 \mathrm{~km}$. This value is consistent with seismic data which suggest that the crust becomes thicker as one moves southwards of the uplift [Stuart et al., 1985]. This area appears to be a transition zone between the "Pan African" and the "cratonic" crust here after presented.

Southern block (grids 25 to 33). $T_{c}$ estimates are more than $30 \mathrm{~km}$ and could be as high as $50 \pm 10 \mathrm{~km}$ in the northern part of the Congolese craton. A larger grid $(333 \mathrm{~km}$ x $666 \mathrm{~km}$ ) produces a $T_{c}$ of about $29 \mathrm{~km}$, which is less than the previous $50 \mathrm{~km}$. This could be due to the data distribution, since the larger grid also includes some areas with very few data. The results show that in the Congolese craton area the crust is thicker than beneath the mobile belts and rifted regions to the north.

\section{Mechanical Behavior of the Lithosphere}

\section{Observed coherence}

The method used to estimate the flexural rigidity $(D)$, or, equivalently the effective elastic thickness $\left(T_{e}\right)$ of the lithosphere, is the coherence function analysis [e.g., Forsyth, 1985]. This method exploits the wavelength dependence between gravity and topography. Flexural models of isostatic compensation for continental lithosphere assume that a thin elastic plate overlying a fluid asthenosphere is deflected by surface (e.g., topographic) and subsurface (e.g., Moho) loads. The amplitude and wavelength of the deflection of the plate thus depend on the flexural rigidity and distribution of the loads. For example, the classical Airy model (local compensation) corresponds to a flexural model where the plate has no rigidity. If the plate has a nonzero rigidity (regional compensation), at short wavelengths, surface and subsurface loads are supported by the rigidity of the lithosphere and the plate is not deflected. As a consequence, the gravity and topography are incoherent and the coherence is close to 0 . At long wavelengths, the plate is deflected by surface loads, and loading from below leads to the formation of topographic reliefs. Therefore gravity and topography are coherent and the coherence is close to 1 . The steep curves at the transitional wavelength where loads are partially supported by plate strength and by flexure give an estimate of the flexural rigidity of the lithosphere (Figure 7). The $T_{e}$ and the flexural rigidity of a plate are related by

$$
D=E T_{e}^{3} /\left[12\left(1-v^{2}\right)\right],
$$

where $E$ is Young's modulus and $v$ is Poisson's ratio.

The observed coherence is computed, in the frequency domain, by [Forsyth, 1985]:

$$
\gamma_{o}^{2}(k)=C_{s}^{2}(k) /\left[E_{H}(k) E_{G}(k)\right]
$$

where $C_{S}{ }^{2}(k)$ is the square of the cross spectrum of gravity and topography, $E_{H}(k)=\left\langle H(k) H^{*}(k)\right\rangle$ is the average spectrum of topography, $E_{G}(k)=\left\langle G(k) G^{*}(k)>\right.$ the average spectrum of gravity, asterisk is the complex conjugation, and $k=|k|$ the two-dimensional wavenumber is equal to $\left(k_{x}^{2}+k_{y}^{2}\right)^{1 / 2}, k_{x}$ and $k_{y}$ are wavenumbers in the $x$ and $y$ directions, respectively. In order to avoid the biasing of the values by noise in the data sets, we computed the coherence using [Munk and Cartwright, 1966]

$$
\gamma^{2}=\left(n \gamma_{0}^{2}-1\right) /(n-1)
$$

where $n$ is the number of independent Fourier coefficients in a given wave band. Note that from (3), if a wave band contains a

Table 1. $T_{c}$ Values and Selected Wavebands for the Regression Lines in Figure 5

\begin{tabular}{ccl}
\hline Grid & Selected Wavebands & Tc, $\mathbf{k m}$ \\
\hline 1 & 7 to 12 & $17.8 \pm 1$ \\
2 & 7 to 10 & $30.2 \pm 1$ \\
3 & 9 to 13 & $16.2 \pm 1$ \\
4 & 8 to 11 & $20.7 \pm 4$ \\
5 & 8 to 14 & $13.6 \pm 2$ \\
6 & 8 to 13 & $14.6 \pm 1$ \\
7 & 8 to 11 & $25.7 \pm 4$ \\
8 & 8 to 11 & $28.8 \pm 6$ \\
9 & 6 to 9 & $33.6 \pm 8$ \\
10 & 6 to 10 & $28.0 \pm 5$ \\
11 & 6 to 10 & $24.4 \pm 3$ \\
12 & 8 to 11 & $25.7 \pm 1$ \\
13 & 6 to 10 & $33.7 \pm 6$ \\
14 & 9 to 15 & $14.9 \pm 1$ \\
15 & 9 to 13 & $18.5 \pm 2$ \\
16 & 7 to 10 & $23.4 \pm 6$ \\
17 & 9 to 14 & $11.4 \pm 1$ \\
18 & 5 to 8 & $16.7 \pm 4$ \\
19 & 6 to 9 & $31.7 \pm 8$ \\
20 & 6 to 10 & $22.6 \pm 3$ \\
21 & 9 to 12 & $22.5 \pm 4$ \\
22 & 10 to 12 & $20.5 \pm 3$ \\
23 & 8 to 11 & $21.2 \pm 8$ \\
24 & 8 to 11 & $22.0 \pm 7$ \\
25 & 8 to 10 & $35.0 \pm 10$ \\
26 & 6 to 10 & $29.7 \pm 1$ \\
27 & 4 to 8 & $32.0 \pm 4$ \\
28 & 7 to 10 & $40.0 \pm 5$ \\
29 & 4 to 8 & $59.0 \pm 3$ \\
30 & 8 to 10 & $47.0 \pm 10$ \\
31 & 6 to 9 & $45.0 \pm 8$ \\
32 & 6 to 10 & $51.0 \pm 10$ \\
33 & 5 to 10 & $45.8 \pm 5$ \\
\hline & & \\
\hline & &
\end{tabular}




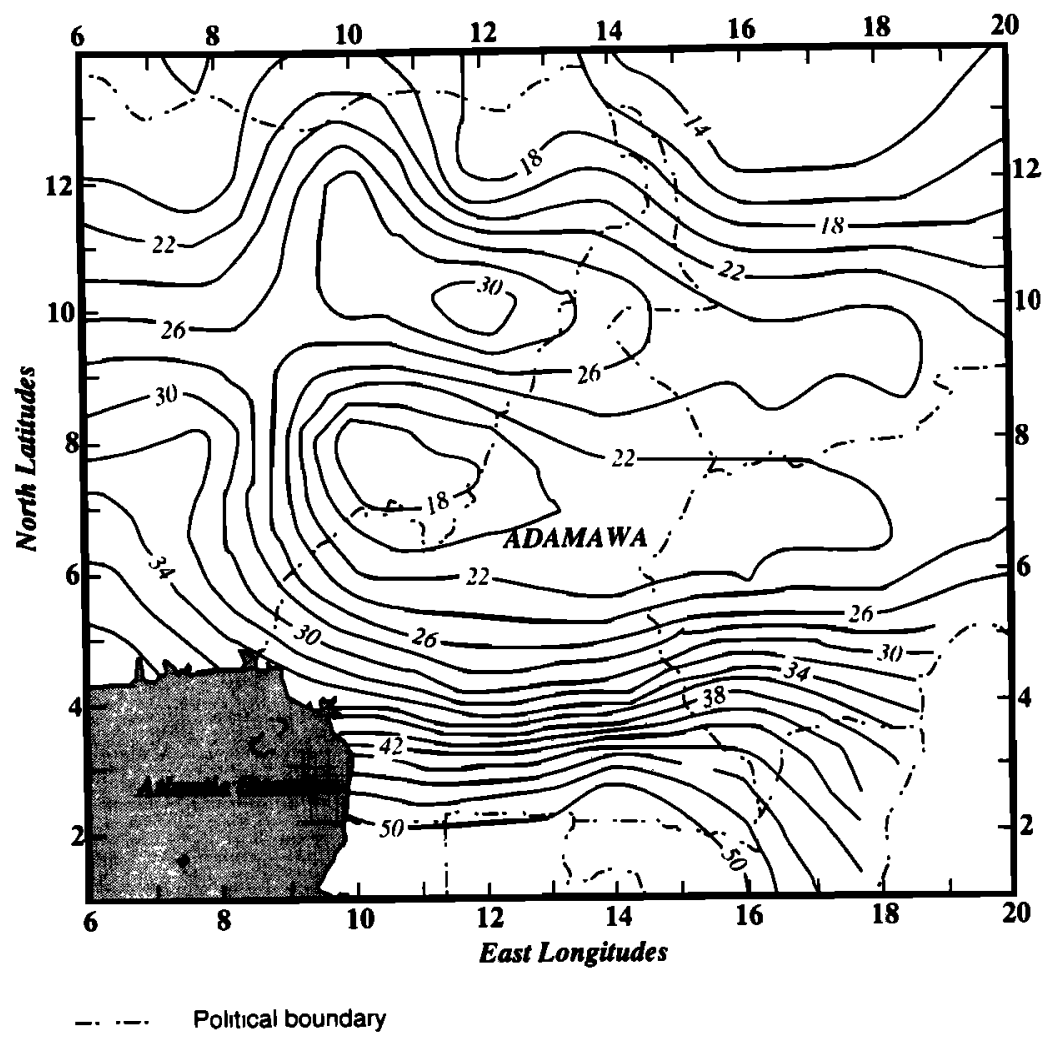

Figure 6. Average crustal thickness contour map of the study area obtained by interpolation of the values in Table 1. Contour interval is $2 \mathrm{~km}$. Note the correlation with tectonic provinces (Figure 1). The Adamawa uplift (center of the map) and the Benue trough (to the west of the Adamawa) are characterized by a crustal thinning $\left(T_{\mathcal{C}}=22-33 \mathrm{~km}\right)$. The Congolese craton in southern Cameroon has a thicker crust $\left(T_{c}>45 \mathrm{~km}\right)$.

small number of points $(n)$ and the coherence $\left(\gamma_{o}{ }^{2}\right)$ is small, then $\gamma^{2}$ could be negative. The standard errors on the coherence within each subregion were computed as follows [Bendat and Piersol, 1980]:

$$
\Delta \gamma^{2}=\left(1-\gamma_{0}{ }^{2}\right)\left(2 \gamma_{0}{ }^{2} / n\right)^{1 / 2}
$$

The method explained here was thus applied to each of the 33 subgrids to compute the observed coherence. The size of the grids was small enough such that the $T_{e}$ does not vary significantly within a region.

\section{Density Model and Inversion for $D$}

We inverted the observed coherence using the method of Forsyth [1985], briefly summarized here. We assume that several factors contribute to the observed Bouguer anomaly in each grid. We also assume that density contrasts occur at two interfaces producing surface topography $(H)$ and relief at the Moho $(W)$. We then chose a simple two-layer density model for all the 33 subgrids (Table 2). This model takes into account both the surface and subsurface loads. Thus, according to this model, the relief on each density contrast has components resulting from loading on the two interfaces [Forsyth, 1985]. The separation of the components of relief on the two interfaces is accomplished with the 2-D Fourier transform of the thin elastic plate equation as follows:

$$
D k^{4} U(k)+\rho_{m} g U(k)=Q(k)
$$

where $D$ is the flexural rigidity, $U(k)$ is the amplitude of the plate deflection, $\rho_{m}$ the mantle density, $g$ is the gravitational acceleration and $Q(k)$ the applied load on a given interface. Using (5), expressions are derived for each component of relief (topographic loading, loading on the Moho) [Forsyth, 1985; Bechtel et al., 1987]. The solution of the system obtained is unique and occurs for $D k^{4} \neq 0$. At wavenumbers where $D k^{4}=0$, surface and subsurface loads are indistinguishable because all loads are locally compensated.

The amplitudes of relief obtained from the further equations are substituted into the power of the topography. The power of gravity is obtained by upward continuation of the relief on the subsurface density contrast [Forsyth, 1985]. After all substitutions in (2), the predicted coherence becomes

$$
\gamma_{o}{ }^{2}=\left\langle H_{t} W_{t}+H_{b} W_{b}\right\rangle^{2} /\left\langle H_{t}^{2}+H_{b}^{2}\right\rangle\left\langle W_{\mathrm{t}}^{2}+W_{b}^{2}\right\rangle
$$

where $H$ is the surface topography, $W$ is the relief at the Moho, and subscripts $t$ and $b$ stand for top (or surface topography) and bottom (or base of the crust) loads, respectively. Equation (6) is simplified by assuming that surface and subsurface loads are independent processes, which means that the cross products $H_{t} W_{t}, H_{b} W_{t}$, etc., in the expressions for the spectra $E_{H}, E_{G}$, and $C_{s}$ are cancelled in the formula for $\gamma_{0}{ }^{2}$. In this case, the flexural rigidity can be determined uniquely [Forsyth, 1985].

For the $\mathbf{3 3}$ grids, we first assume a flexural rigidity and solve for $H_{t}, H_{b}, W_{t}$, and $W_{b}$. After that, we estimate the predicted coherence using (6) for a range of flexural rigidities. 

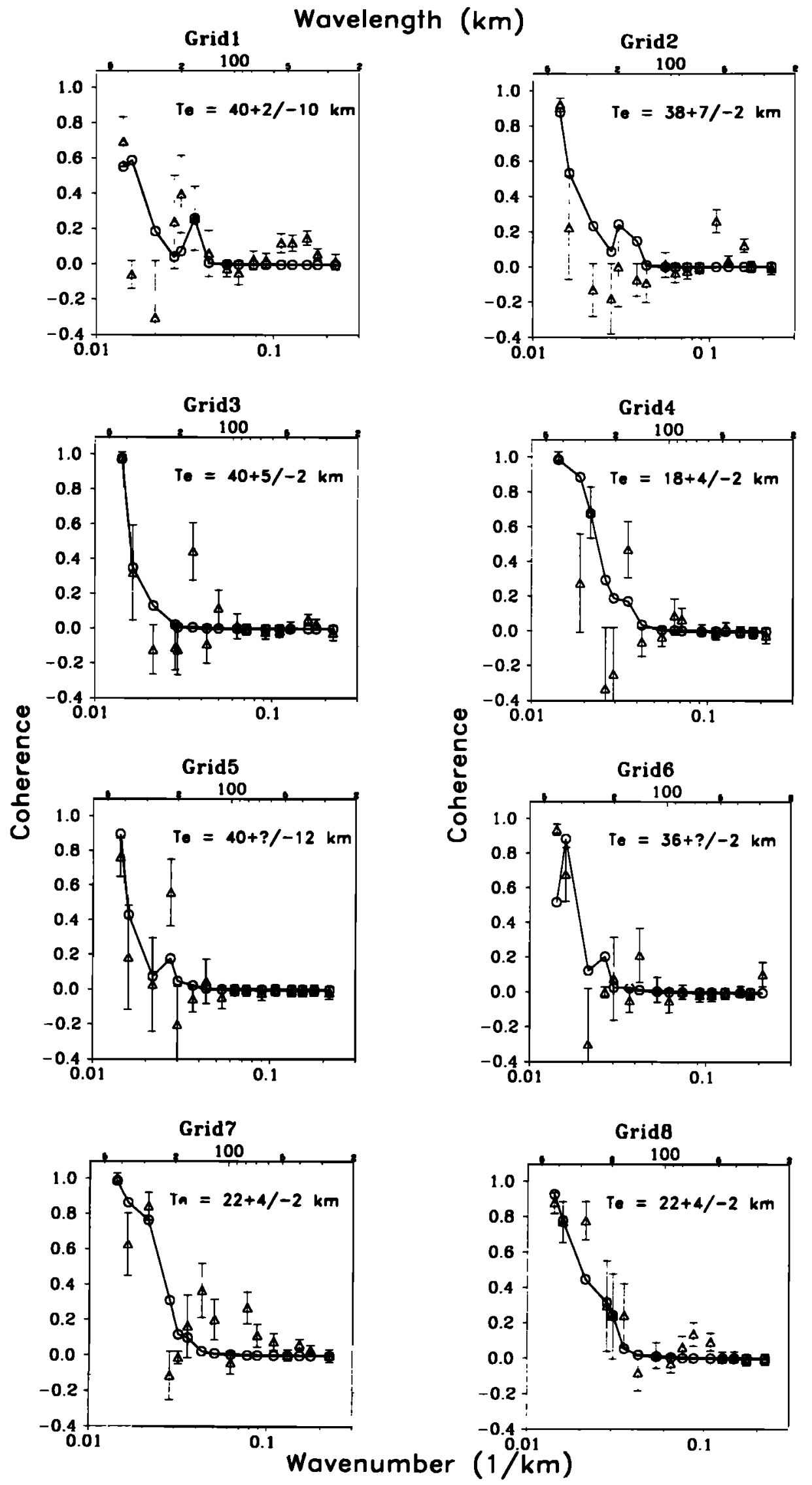

Figure 7. Comparison between observed coherence (the triangles) and predicted coherence (circles) corresponding to the best fitting models for the large box of Chad area (grid Chad) and each of the 33 grids of Figure 3. The $T_{e}$ values are indicated for each plot and listed on Table 3 with the rms errors. 

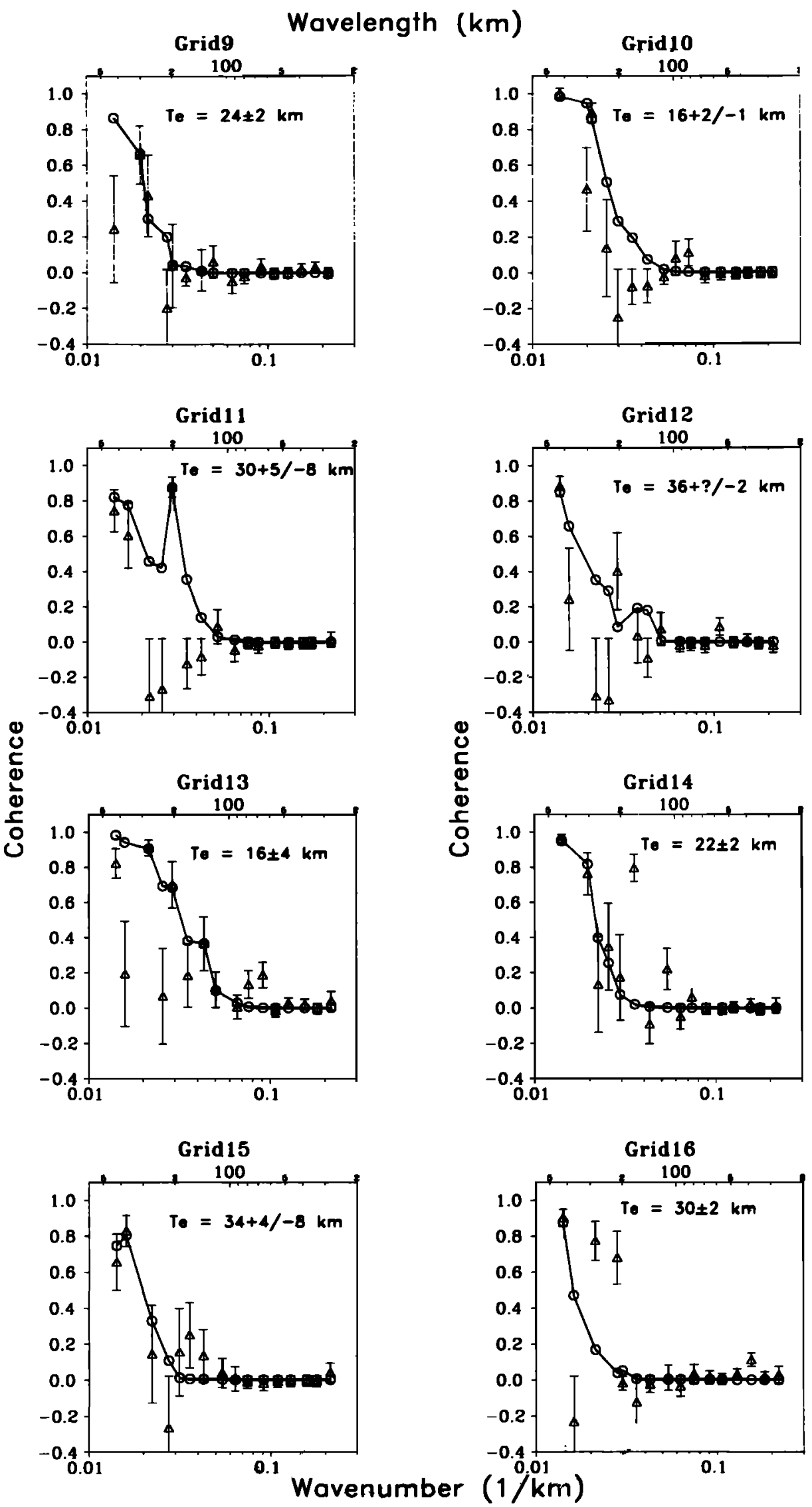

Figure 7. (continued) 

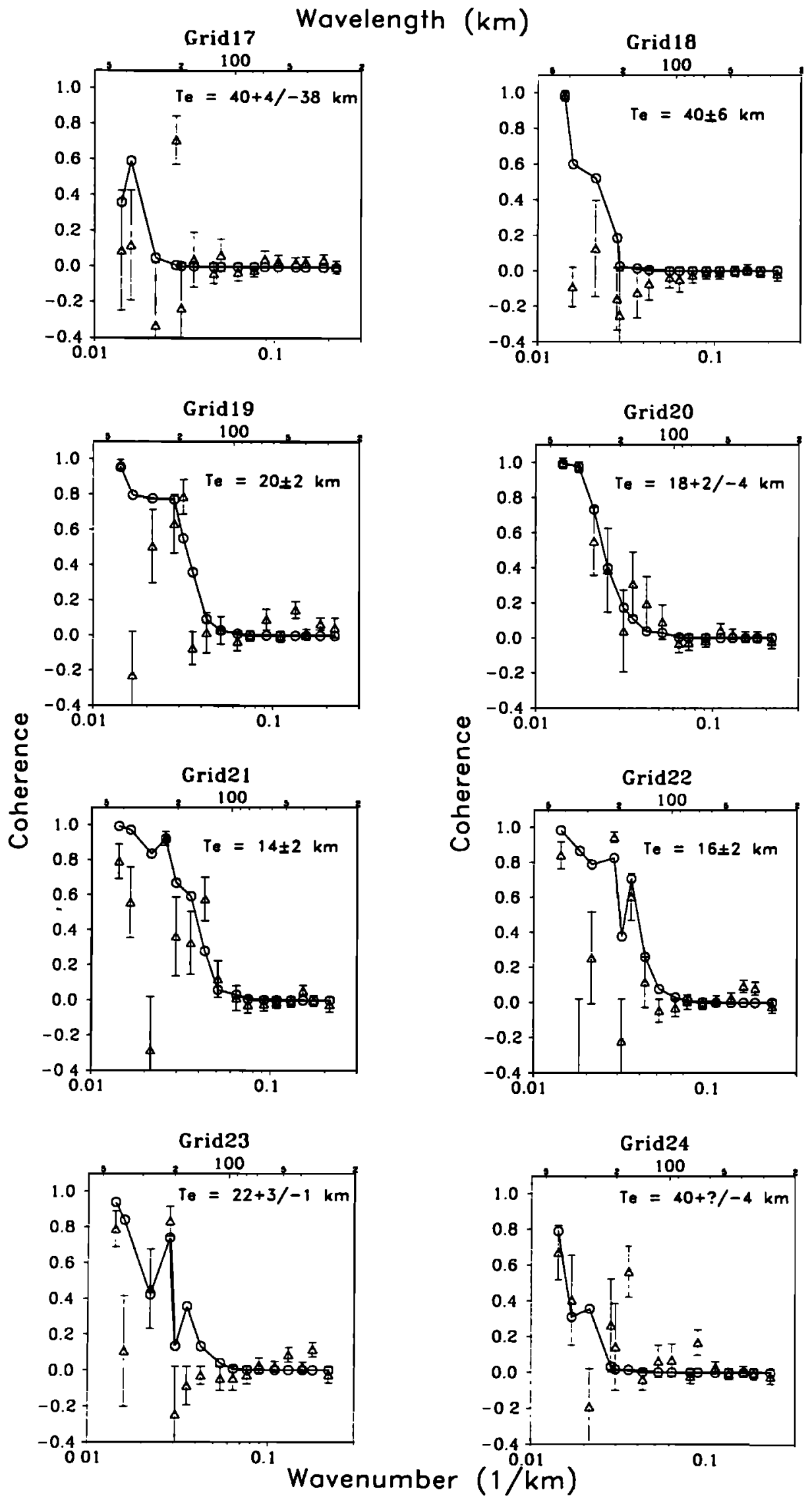

Figure 7. (continued) 

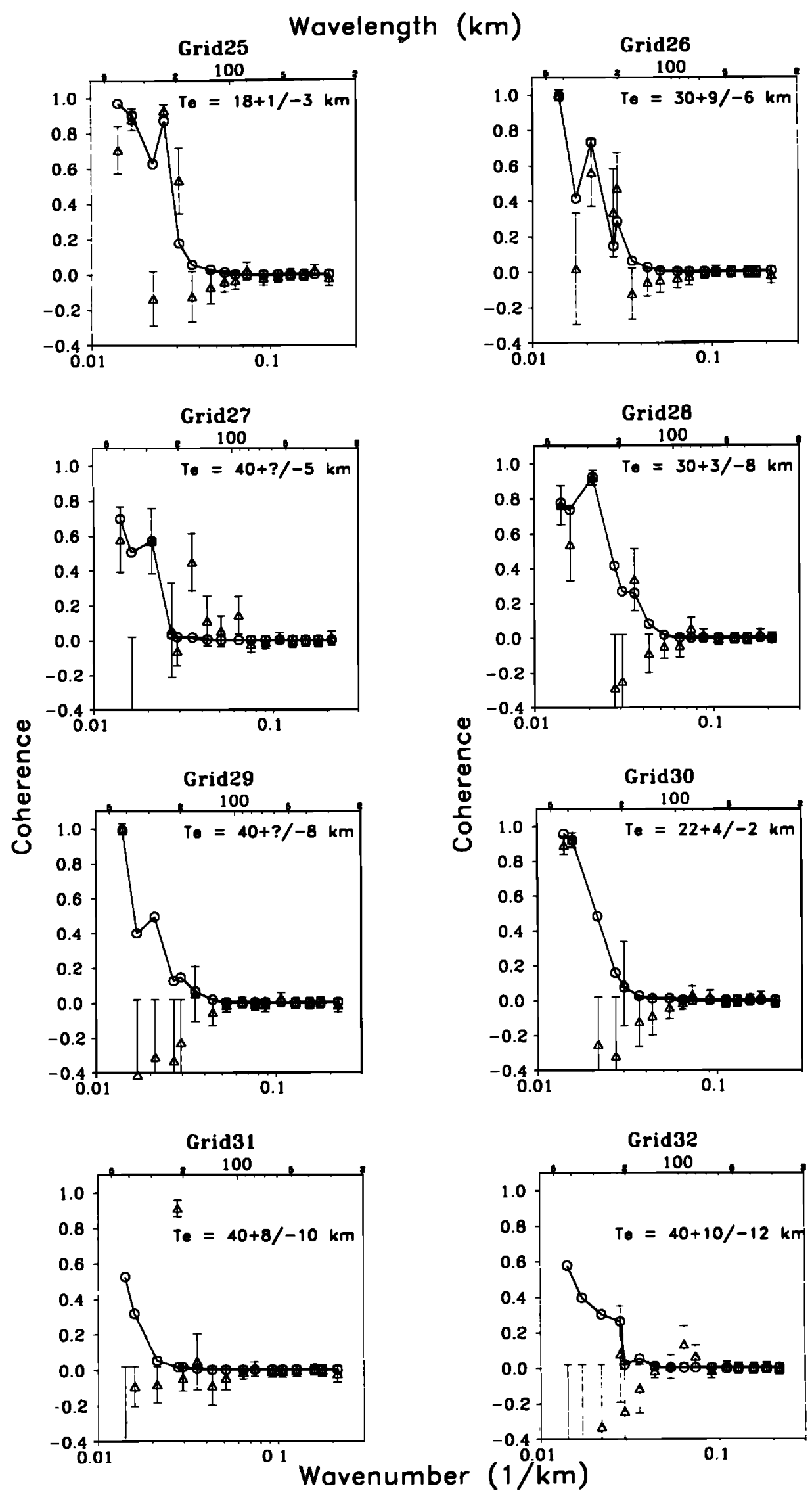

Figure 7. (continued) 


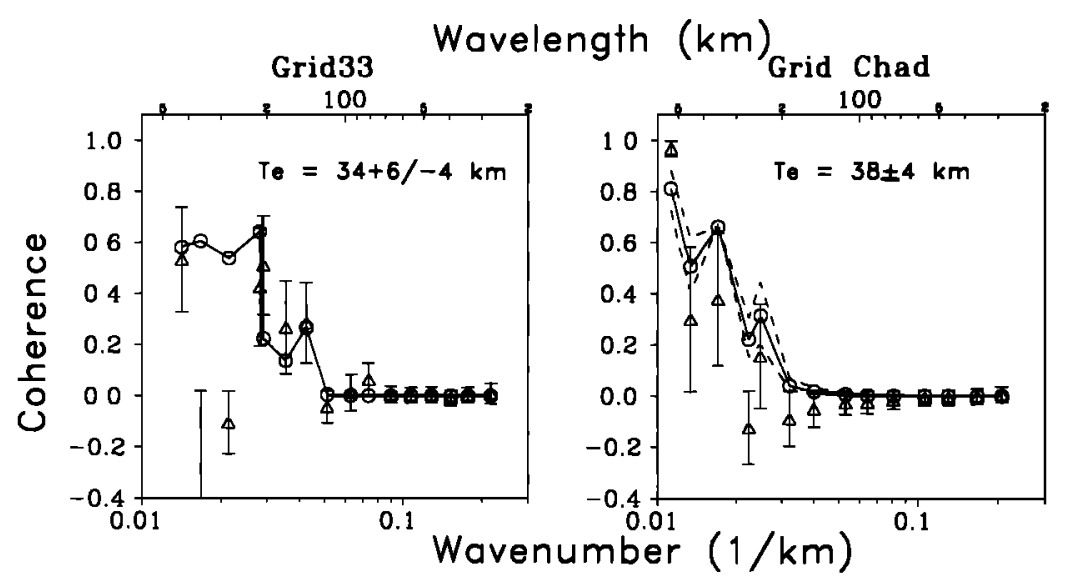

Figure 7. (continued)

Crustal and mantle densities of $2670 \mathrm{~kg} / \mathrm{m}^{3}$ and $3300 \mathrm{~kg} / \mathrm{m}^{3}$, respectively, were assumed for each subregion. As an independent check on our $T_{c}$ estimates, we varied the crustal thickness from 10 to $40 \mathrm{~km}$ in each region. The best fitting elastic plate thickness for each subregion is obtained by minimising the residuals between the observed and predicted coherence. After a series of tests on grid 21 (the Adamawa uplift) where constraints on the Moho depth exist from seismic refraction data [Stuart et al., 1985], we estimated the residuals by a one-norm misfit method [e.g., Parker and McNutt, 1980]. It is important to note that the misfit error estimated in this case is higher than that reported in earlier studies [e.g., Bechtel et al., 1987]. Table 2 shows a listing of the physical parameters used to estimate the observed and predicted coherence for all the subregions.

\section{Description of Coherence Models}

The observed coherence and the best fit model of computed coherence for the 33 subgrids are shown in Figure 7. These plots allow comparison between elastic plate thickness beneath active and inactive volcanic areas, sedimentary basins and cratonic subregions. For all the grids, the coherence is close to zero at short wavelengths and gradually approaches 1 at long wavelengths where the plate is weak and deflected by surface and/or subsurface loads. At short wavelengths, the plate is strong enough to support topographic loads with no corresponding Bouguer gravity anomalies. The transition from low to high coherence occurs within a narrow wave band, with large error bars caused by wavenumber averaging in fall-

Table 2. Physical Parameters Used for the Estimation of the Observed and Predicted Coherence

\begin{tabular}{lll}
\hline Parameters & \multicolumn{1}{c}{ Definitions } & \multicolumn{1}{c}{ Value } \\
\hline$Z_{m}$ or $T_{c}$ & $\begin{array}{c}\text { Moho depth, depth to } \\
\text { subsurface load }\end{array}$ & $10-40 \mathrm{~km}$ \\
& $\begin{array}{l}\text { average crustal density } \\
\rho_{c}\end{array}$ & $2670 \mathrm{~kg} \mathrm{~m}^{-3}$ \\
$\rho_{m}$ & upper mantle density & $3300 \mathrm{~kg} \mathrm{~m}^{-3}$ \\
$g$ & gravity acceleration & $9.8 \mathrm{~m} \mathrm{~s}^{-2}$ \\
$G$ & gravitational constant & $6.67 \times 10^{-11} \mathrm{~m}^{3} \mathrm{~kg}^{-1} \mathrm{~s}^{-2}$ \\
$E$ & Young's modulus & $1 \times 10^{11} \mathrm{~N} \mathrm{~m}^{-2}$ \\
$\mathrm{v}$ & Poisson's ratio & 0.25 \\
$T_{e}$ & effective elastic thickness & inverted \\
$D$ & flexural nigidity & $\mathrm{E} \mathrm{T}^{3}\left[12\left(1-\mathrm{v}^{2}\right)\right]^{-1}$ \\
\hline
\end{tabular}

off wave bands. As discussed below, the transition may be more broad and show scatter, indicating that the region considered is not uniformly rigid (e.g., Figure 7, grid 7). In that case, the resulting coherence represents an average of subregions with different flexural rigidities weighted by the product of the powers of gravity and topography. Comparing the observed and predicted coherence allows us to determine the flexural rigidity and thus the effective elastic thickness; evidently, the transitional wave band is shifted to longer wavelengths with increasing flexural rigidity [Forsyth, 1985].

The coherence models for grids $1,2,3$, and 4 have to be interpreted with care because of a lack of data in these areas. Thus, while computing an elastic thickness map, these values are rejected. For grids $30,31,32$, and 33 , the coherence is not well constrained and the values are also rejected. The $T_{e}$ values obtained for each region and the corresponding root-meansquare (rms) errors are listed on Table 3.

\section{Error Estimations of $\mathbf{T}_{\mathbf{e}}$}

Several methods can be used to estimate the errors on $T_{e}$ values. The common way is to find the minimum and maximum values of $T_{e}$ that fit the same number of points in the fall-off wave band, as the best fitting coherence model [e.g., Ebinger et al., 1989]. In this study, we used a different approach. For each grid, $T_{e}$ and $T_{c}$ are varied within a range of values, and the best fitting model corresponds to the $\left(T_{e}, T_{c}\right)$ couple with the smallest rms error which measures the residual between the observed and predicted coherence. The results show that the rms errors lie between 0.55 and 1.83 (Table 3 ). The lower value corresponds to grid 20 located at the Benue trough axis, while the highest error is obtained for grid 6 , the eastern part of Chad basin. Since both parameters are varied, we can draw, for each grid, a rms error contour map for $T_{c}$ versus $T_{e}$. After we have selected the best fitting model $\left(T_{e}\right)$, the shaded region in each rms error contour drawing sets the upper and lower confidence limits for $T_{e}$ (Figure 8). The minimum rms residual is increased by no more than 0.12 to give the rms contour for the limits to $T_{e}$. This approach is illustrated in Figure 8, and the minimum and maximum $T_{e}$ curves for the three selected grids $(20,2,6$ and 5) are also shown. For the first contour map (Figure 8a, grid 20), the best fitting model gives a $T_{e}$ value of $18 \mathrm{~km}$ (with $T_{c}=28 \mathrm{~km}$ ), the minimum is $14 \mathrm{~km}$ and the maximum is $20 \mathrm{~km}$. Thus the $T_{e}$ value for this grid is $18+2 /-4 \mathrm{~km}$. Figure $8 \mathrm{~b}$ (grid 26) shows that the best fitting model corresponds to a $T_{e}$ of $30 \mathrm{~km}\left(T_{c}=\right.$ 
Table 3. $T_{e}$ Values for the 33 Subgrids

\begin{tabular}{|c|c|c|c|c|c|c|}
\hline Grid & $\begin{array}{l}\text { Minimal } \\
\text { ms Error }\end{array}$ & $\begin{array}{c}T_{\text {emin }}, \\
\text { km }\end{array}$ & $\begin{array}{l}T_{e}, \\
\mathrm{~km}\end{array}$ & $\underset{\text { km }}{T_{\text {emax }}}$ & $\begin{array}{l}T_{\mathrm{c}} \\
\mathrm{km}\end{array}$ & $\begin{array}{c}D, \\
\times 10^{23} \mathrm{~N} \mathrm{~m}\end{array}$ \\
\hline 1 & 1.64 & 30 & 40 & 42 & 10 & 5.7 \\
\hline 2 & 1.28 & 36 & 38 & 45 & 38 & 4.8 \\
\hline 3 & 0.84 & 38 & 40 & 45 & 32 & 5.7 \\
\hline 4 & 0.86 & 16 & 18 & 22 & 12 & 0.5 \\
\hline 5 & 0.58 & 28 & 40 & $>40$ & 10 & 5.7 \\
\hline 6 & 1.83 & 34 & 36 & $\geq 40$ & 10 & 4.1 \\
\hline 7 & 1.51 & 20 & 22 & 26 & 40 & 0.9 \\
\hline 8 & 0.78 & 20 & 22 & 26 & 28 & 0.9 \\
\hline 9 & 0.66 & 22 & 24 & 26 & 10 & 1.2 \\
\hline 10 & 0.99 & 15 & 16 & 18 & 10 & 0.3 \\
\hline 11 & 0.96 & 22 & 30 & 35 & 38 & 2.4 \\
\hline 12 & 0.99 & 34 & 36 & $\geq 40$ & 14 & 4.1 \\
\hline 13 & 0.97 & 12 & 16 & 20 & 38 & 0.3 \\
\hline 14 & 1.17 & 20 & 22 & 24 & 14 & 0.9 \\
\hline 15 & 0.56 & 26 & 34 & 38 & 40 & 3.5 \\
\hline 16 & 1.46 & 28 & 30 & 32 & 10 & 2.4 \\
\hline 17 & 1.08 & 38 & 40 & 44 & 10 & 5.7 \\
\hline 18 & 1.02 & 34 & 40 & 46 & 10 & 5.7 \\
\hline 19 & 1.45 & 18 & 20 & 22 & 40 & 0.7 \\
\hline 20 & 0.55 & 14 & 18 & 20 & 28 & 0.5 \\
\hline 21 & 1.14 & 12 & 14 & 16 & 38 & 0.2 \\
\hline 22 & 1.57 & 14 & 16 & 18 & 40 & 0.3 \\
\hline 23 & 1.49 & 23 & 22 & 25 & 40 & 0.9 \\
\hline 24 & 1.01 & 36 & 40 & $>40$ & 10 & 5.7 \\
\hline 25 & 1.10 & 15 & 18 & 19 & 10 & 0.5 \\
\hline 26 & 0.62 & 24 & 30 & 39 & 40 & 2.4 \\
\hline 27 & 0.72 & 35 & 40 & $\geq 40$ & 22 & 5.7 \\
\hline 28 & 0.73 & 22 & 30 & 33 & 38 & 2.4 \\
\hline 29 & 0.71 & 32 & 40 & $>40$ & 32 & 5.7 \\
\hline 30 & 0.71 & 20 & 22 & 26 & 14 & 0.9 \\
\hline 31 & 1.96 & 30 & 40 & 48 & 10 & 5.7 \\
\hline 32 & 0.76 & 28 & 40 & 50 & 10 & 5.7 \\
\hline 33 & 0.86 & 30 & 34 & 40 & 40 & 3.5 \\
\hline Chad & 1.02 & 34 & 38 & 42 & 14 & 4.8 \\
\hline
\end{tabular}

The rms error was estimated by a one-norm misfit, and is the residual between the observed and predicted coherence. $T_{e}$ and $T_{c}$ values for each subgrid thus correspond to the smallest $\mathrm{rms}$ error. $T_{\text {emin }}$ and $T_{\text {emax }}$ represent the minimum and maximum $T_{e}$ values, respectively, determined from $\mathrm{mms}$ error contour maps (Figure 8 ). $D$ is the corresponding average flexural rigidity.

$40 \mathrm{~km})$. The minimum and maximum $T_{e}$ values are 24 and 39 $\mathrm{km}$, respectively. In a third case, if the best fitting model yields a $T_{e}$ estimate of $40 \mathrm{~km}$ which is the upper boundary of our predicted models ( $T_{e}$ was varied from 10 to $40 \mathrm{~km}$ ), then the upper limit of the models is modified to resolve for the maximum $T_{e}$ value. This is illustrated in Figure 8c (grid 5), where the minimum rms error corresponds to a $T_{e}$ and $T_{c}$ of 40 and $10 \mathrm{~km}$, respectively. The minimum of $T_{e}$ is $28 \mathrm{~km}$, and the maximum is out of limit. Note that although $T_{c}$ is not well constrained by the inversion of the coherence in most cases (e.g., Figure 8), the values on Table 1 are within the range of those of Table 3 if we consider the error bar on $T_{e}$ values.

\section{Tectonic Subregions: Implications for Lithospheric Structure}

$T_{e}$ values of Table 3 were interpolated to compute an elastic thickness map for Cameroon and adjacent areas. Regions with poorly determined coherence curves were rejected. The resulting $T_{e}$ map (Figure 9) shows that $T_{e}$ is minimum beneath the Cretaceous rifted and active volcanic areas $(14-20 \mathrm{~km})$, increases to $24 \mathrm{~km}$ in the Precambrian belt of the Central African Republic, and, finally, is greatest in cratonic areas ( $40 \mathrm{~km}$ ). This variation shows a relationship between the $T_{e}$ values and the tectonic provinces. We compare the $T_{e}$ and $T_{c}$ maps with the tectonic and geologic map of the area, and their implications for lithospheric-structure beneath active and ancient tectonic belts (Figure 1).

Benue and Yola rifts (grids 7, 8, 9, 10, 13, 14, 19, and 20). The Benue trough was formed during Cretaceous times at the opening of the South Atlantic Ocean. A period of basin inversion occurred during Santonian times $(85 \mathrm{Ma}$ ) and was more intense in the lower Benue than in the middle and upper parts where it occurred some $5 \mathrm{~m} . y$. later. So, the lower Benue may be hotter than the Yola and Gongola branches of the rift.

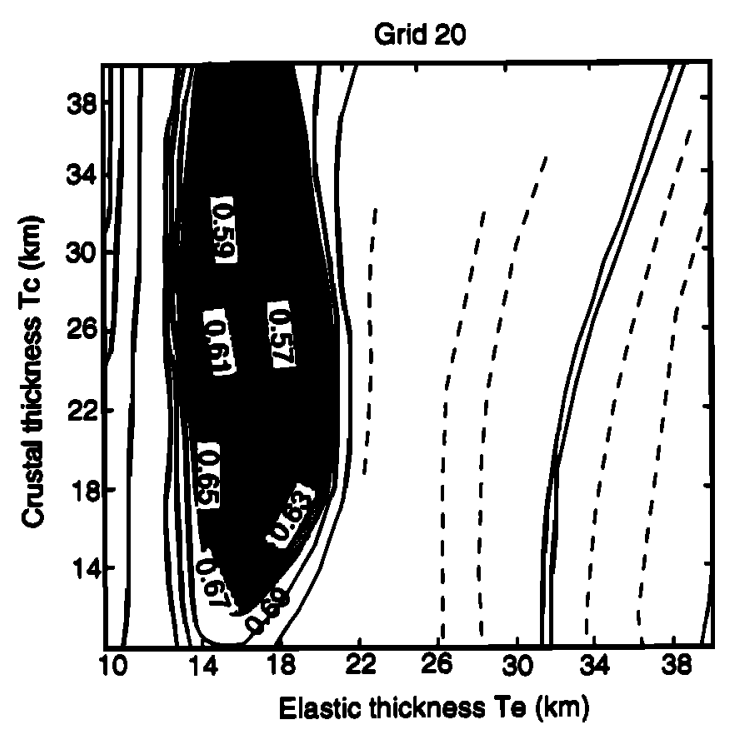

Grid 20

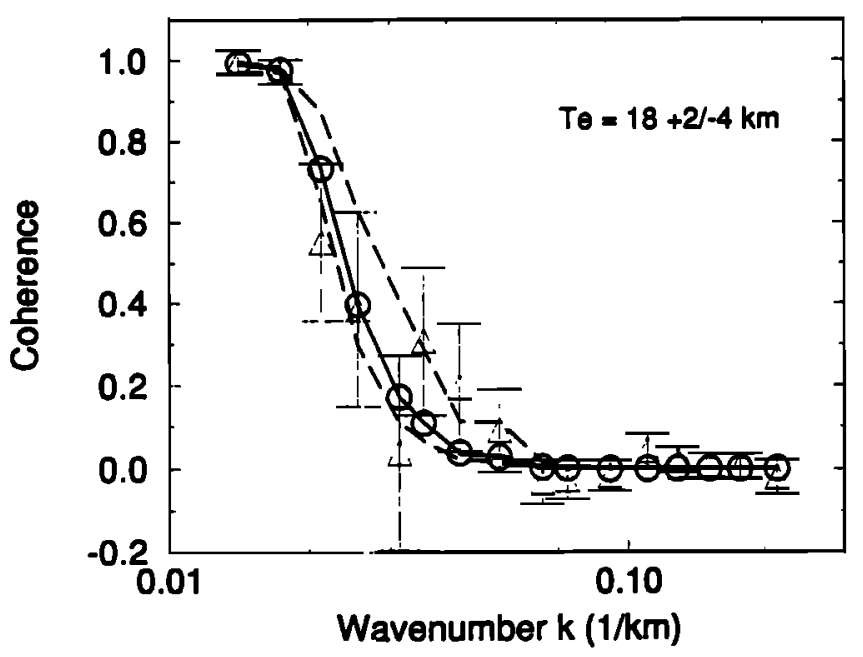

Figure 8a. Example of rms residual error contour map for error estimations on $T_{e}$, and corresponding coherence model curves (grid 20). The shaded zone in the rms diagram defines the zone of confidence on $T_{e}$ values and the upper and lower limit on $T_{e}$. Solid lines and circles are the best fitting coherence models, long-dashed lines are the minimum and maximum $T_{e}$ curves. 


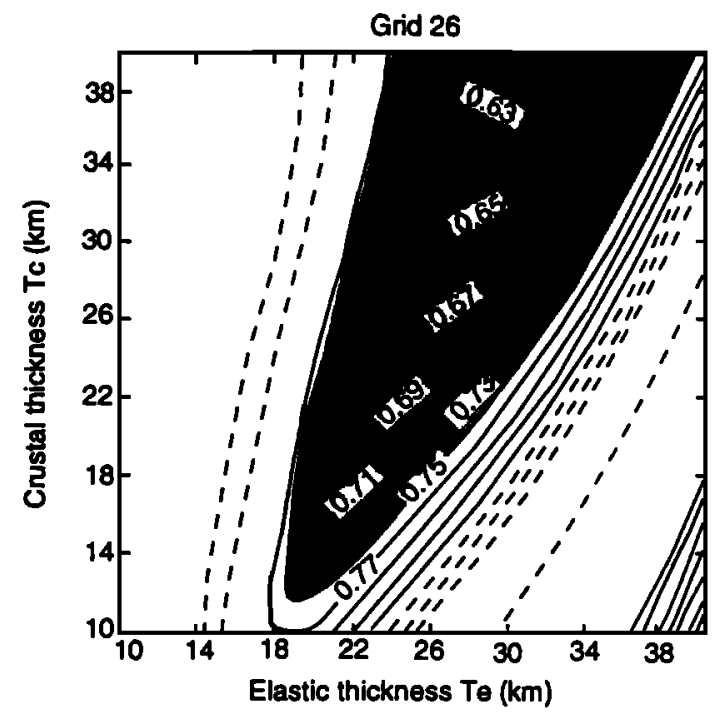

Grid 26

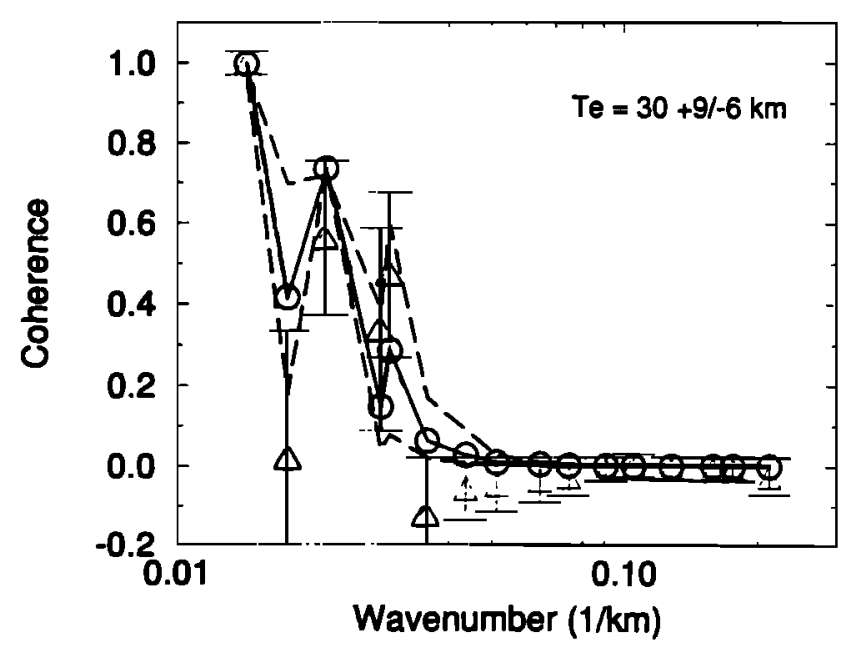

Figure 8b. Same as Figure 8a except for grid 26.

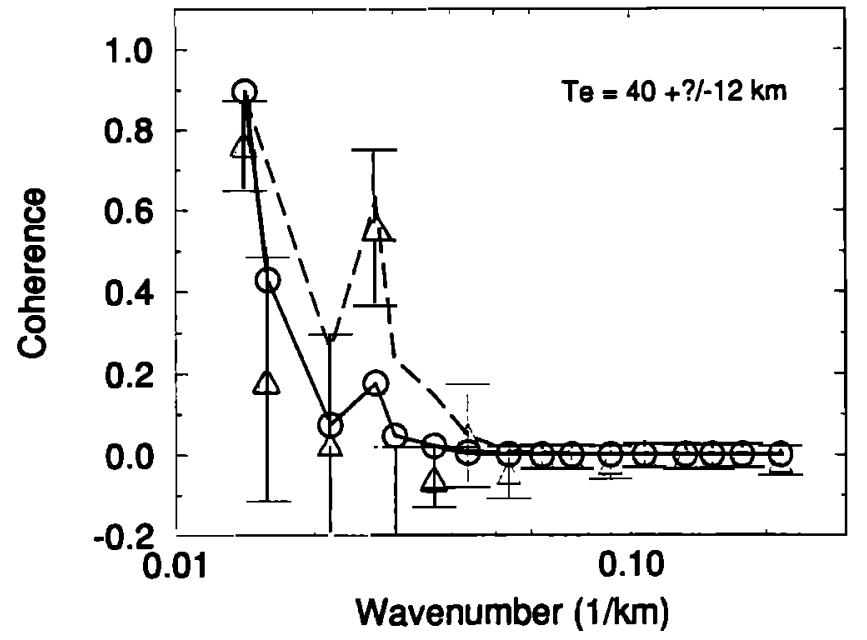

Figure 8c. Same as Figure 8a except for grid 5.

Grid 7 shows a great scatter of the observed coherence. The corresponding model gives an estimate of $T_{e}=22+4 /-2 \mathrm{~km}$. The observed coherence could correspond to a combination of different tectonic features and thus different rigidities. A correlation of this grid with the geological map shows that it is formed of both a part of the Jurassic Jos plateau and the Cretaceous Benue trough. The combination of these geological units results in a high rms error (1.51) for the best fitting model. Grid 8 is rather well constrained, and the transitional wave bands show a smooth fall-off of the curve, suggesting a uniformly rigid area.

The coherence models for these rifts yield a $T_{e}$ that varies from $16 \mathrm{~km}$ in the south to $23 \mathrm{~km}$ in the north of the Benue trough. These values are relatively low and show that the lithosphere is weak beneath the Benue rift. The $T_{e}$ values obtained here for the Benue trough can be compared to those of other active rifted areas such as the Kenya rift valley (26-35 km) [Bechtel et al., 1987; Ebinger et al., 1989], the Baikal rift $(30 \mathrm{~km})$ [Diament and Kogan, 1990], and South Australia basins $(23 \mathrm{~km})$ [Zuber et al., 1989].

Cameroon Volcanic Line (grids 20 and 25). These volcanic centers cover a part of the CASZ in southwest Cameroon. The coherence model for grid 20 fits all the values of the observed coherence in the transitional wave band, suggesting a uniformly rigid zone. Grid 25 rather shows scatter and negative coherence values. This grid is selected near the coast line, and the scatter could be related to errors due to the interpolation of the data prior to the computations. The best fitting coherence models for the two grids yield $T_{e}$ of 18 $+2 /-4 \mathrm{~km}$. This value suggests a weak lithosphere beneath the volcanoes of the Cameroon Volcanic Line.

Adamawa uplift (grids 16, 21, and 22). These grids show scattered values for the observed coherences. These areas are not well covered by data, so the transitional wave band is sensitive to the lack of data which biases to stronger values of $T_{e}$ [e.g., Ebinger et al., 1989], and the corresponding rms error is greater than 1 (1.14-1.57). The $T_{e}$ value obtained is $14-16 \mathrm{~km}$. This value is low in comparison to the surrounding areas: the Yola rift to the north $(22 \mathrm{~km})$ and the Congolese craton to the south $(30 \mathrm{~km})$. A $T_{e}$ estimate of $20 \mathrm{~km}$ was also 


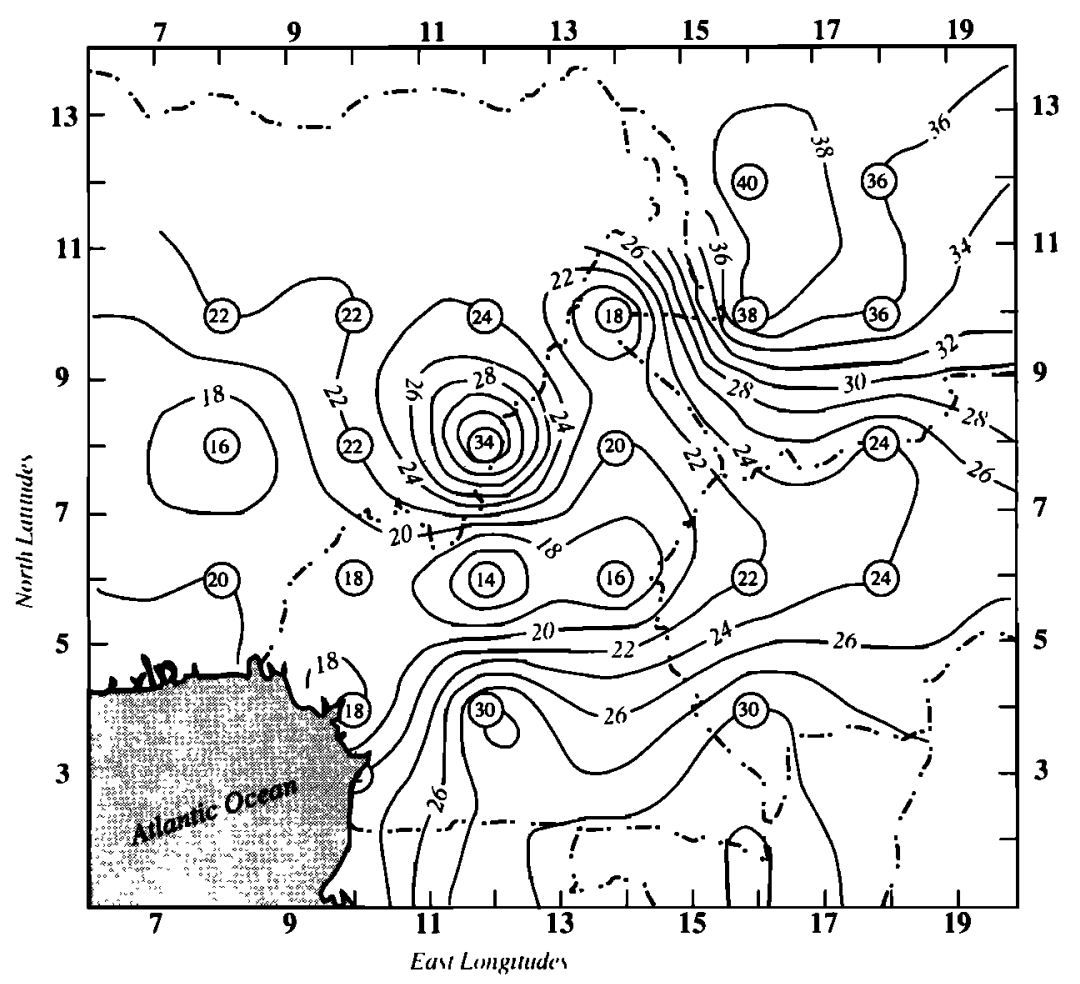

Figure 9. Effective elastic thickness $\left(T_{e}\right)$ contour map of west central Africa. Contour interval is $2 \mathrm{~km}$. The values used to compute the map are listed in Table 3 and shown here in small circles at the center of each grid. Note the correlation with the tectonic provinces and the $T_{c}$ map (Figures 1 and 6 , respectively). The minimum of $T_{e}$ corresponds to the active volcanoes and rifts (CVL, Adamawa uplift and Benue rift), and the maximum corresponds to the Congolese craton. The minimum of $T_{e}$ also correlates with the minimum of $T_{c}$ in the Adamawa region (Figure 6).

obtained by a two-dimensional study of this uplift [Poudjom Djomani et al., 1992]. This $T_{e}$ value for the Adamawa plateau is slightly less than the $20-50 \mathrm{~km}$ of other active volcanic plateaux in Africa [e.g., Lesquer et al., 1988; Bonvalot, $1990]$.

Benue-CVL border (grid 15). The $T_{e}$ map shows a series of concentric contours between the Benue trough and the CVL. The coherence plot for this grid shows a scatter of the points in the transitional wave band. The rms error for the best fitting coherence model is 0.56 , and the $T_{e}$ is $34+4 /-8 \mathrm{~km}$. There is no particular geological feature associated to this area, and the $T_{e}$ value suggests a strong lithosphere between the Benue rift and the CVL.

Chad basins/craton? (grids 5, 6, 11, and 12). The coherence models for these grids are constrained by very few points in the transitional wave band and characterized by large error bars. The rms errors lie between 0.58 (grid 5) and 1.83 (grid 6), and $T_{e}$ varies from 36 to $40 \mathrm{~km}$. The grids may be too small to show a good transition from 1 to 0 for such high $T_{e}$ (> $36 \mathrm{~km}$ ). In order to better constrain our result, we selected a larger grid for this region $(555 \times 444 \mathrm{~km})$. The $T_{e}$ estimate from the large grid is about $38 \mathrm{~km}$ (Figure 7, grid Chad). This grid shows that the transition from 1 to 0 occurs at approximately the same wave bands as the previous grids ( 5 and 6), suggesting that the grids were large enough to resolve $T_{e}$ in this region. The result suggests a strong lithosphere in this area, and this could be compared to the values on the Congolese craton described as follows.

Congolese craton (grids 26, 27, and 28). The northern part of this craton is in southern Cameroon. The ENE-WSW
Sanaga fault zone cuts across the area. The rms errors between the observed and predicted coherence for the three grids are between 0.62 and 0.72 , and $T_{e}$ ranges from 30 to $40 \mathrm{~km}$ but could be more. The $T_{e}$ values obtained here suggest that the lithosphere is strong in this area. As a comparison, these values are smaller than those of other stable cratonic areas such as Sudan (64-79 km) [Ebinger et al., 1989], Australia $(>120 \mathrm{~km})$ [Zuber et al., 1989], Canada (>134 km) [Pilkington, 1991], and South Africa (76 km) [M. Mushayandebvu, personal communication, 1994]. This may be caused by the active Sanaga fault zone in the area and by the rejuvenation of this craton between 2300 and $1800 \mathrm{Ma}$, which means that this craton is younger than the others cited above.

\section{Discussion}

Figures 6 and 9 show $T_{C}$ and $T_{e}$ variations, respectively, in Cameroon and the adjacent countries. Tc varies from 14 to 45 $\mathrm{km}$, while the minimum and maximum of $T_{e}$ are 14 and $40 \mathrm{~km}$ or more, respectively. Comparing the $T_{e}$ and $T_{c}$ maps shows that the minimum of $T_{e}$ roughly corresponds to the minimum of $T_{c}$; these minima lie beneath the Adamawa volcanic uplift in Central Cameroon. Our aim now is to point out the relationships between the $T_{e}, T_{c}$ values, and the evolution of the different tectonic provinces within the study area.

The Cretaceous Benue trough is characterized by a relatively low $T_{e}(16-23 \mathrm{~km})$. This trough has undergone several thermal tectonic events during geological times, one of which resulted in NE-SW trending faulted and folded anticline and syncline structures. These events could have 
weakened the crust. The crustal thickness varies from $15 \mathrm{~km}$ (lower Benue) to $33 \mathrm{~km}$ (upper Benue), and the Yola rift is characterized by a $25-\mathrm{km}$-thick crust. A combined interpretation of geological and geophysical data suggests that the Benue trough was subjected to major tectonic extension and shear deformation phases. These results also suggest a zone of weakness in the lower crust, as well as a mechanically weak lithosphere.

The active volcanoes of the CVL in southwestern Cameroon are characterized by a relatively low $T_{e}(18+2 /-4$ $\mathrm{km}$ ). Gas emissions have occurred in this area, in Lakes Monoun in 1984 and Nyos in 1986 [e.g., Njilah, 1991]. Geochemical data suggest that the basaltic rocks of the oceanic and continental sectors of the line have some similarities [Halliday et al., 1990; Njilah, 1991]. Those of the continental part seem to be contaminated by a thick sialic crust. On the other hand, the isotopic compositions of the rocks of the ocean/continent boundary are close to that of the St. Helena chain in the Atlantic Ocean, suggesting the same partial melt and fractionization processes and high temperature in the upper mantle [e.g., Halliday et al., 1990]. Seismic studies revealed that the Mount Cameroon upper mantle is characterized by low-velocity bodies [Tabod, 1991]. The area is also characterized by a normal $35-\mathrm{km}$ continental crust. The important implication of these related studies is that the lithosphere beneath the CVL is weak, probably due to thermal and magmatic activities.

The Adamawa volcanic uplift, which is the northeastern limit of the CVL, has a relatively low $T_{e}(14-16 \mathrm{~km})$. This uplift is characterized by a long-wavelength negative Bouguer anomaly and altitudes greater than $800 \mathrm{~m}$. Teleseismic delay time studies revealed the presence of anomalously hot upper mantle beneath the Adamawa uplift [Dorbath et al., 1986]. The depth to this anomalous body (70 to $90 \mathrm{~km}$ ) was inferred from spectral analysis of the gravity data [Fairhead and Okereke, 1988; Nnange, 1991; Poudjom Djomani et al., 1992, 1993]. The gravity studies suggest that this upper mantle body is the source of the negative gravity anomaly [e.g., Poudjom Djomani, 1993]. By analogy to oceanic swells, Ebinger et al. [1989] suggested that weakening of the lithosphere beneath volcanically active continental swells, as the Adamawa uplift here, could be due to thermal activity.

The Adamawa uplift is also characterized by the CASZ, a major dextral shear associated with mylonite belts. These mylonites originate from a dynamic or high-grade metamorphism resulting in mineral crushing and thus delineate a weak zone. Recent earthquakes of magnitude 4.8 and focal depth $10-11 \mathrm{~km}$, with epicenters located along the Foumban shear zone, part of the CASZ, have been recorded [Nnange et al., 1985; Nnange, 1988] suggesting that the area has been reactivated in Recent times. The crustal thickness in this area determined in this study is about $22 \mathrm{~km}$ and is consistent with seismic refraction studies and petrologic data [Girod et al., 1984]. These geological and geophysical results suggest that the lithosphere is weak beneath the Adamawa uplift and thus beneath the CVL. This zone of weakness may be a preferred conduit for magma to reach the surface.

Of a different interest are the Congolese craton and the Chad basins. These areas are characterized by higher $T_{e}$ values $(\sim 40 \mathrm{~km})$. As we have previously discussed, although the values are great, they are still small as compared to those of other stable cratonic areas. In the Congolese craton, the average crustal thickness deduced from gravity data is $40 \mathrm{~km}$ and there is a positive relationship here between $T_{e}$ and $T_{c}$, with thick crust (high $T_{c}$ ) correlated with relatively high $T_{e}$. In the Chad basins, the Bouguer anomaly map shows positive anomalies with patterns similar to those of the well known West African craton border (Plate 2). These anomalies are interpreted by Louis [1970] and Freeth [1984] as an hypothetical suture zone of Pan-African origin (Nilotic craton border). The $T_{e}$ value $(38+4 /-4 \mathrm{~km})$ suggests a stronger lithosphere, but the spectral analysis of the gravity data leads to a depth estimation $\left(T_{c}\right)$ of about $15 \mathrm{~km}$, which is much less than a normal cratonic crust.

\section{Conclusions}

This study shows that there is generally a positive correlation between crustal thickness $\left(T_{c}\right)$ and effective elastic thickness $\left(T_{e}\right)$ of the lithosphere, with low $T_{c}$ values corresponding to relatively low $T_{e} . T_{c}$ variations generally result in coupling or decoupling of the crust with the mantle lithosphere. This behavior of the mechanical crust and upper mantle leads to variations in $T_{e}$ estimates. For example, if the crust and mantle are mechanically coupled (low temperature and/or thin crust), $T_{e}$ should follow, as for the oceans, the depth to the base of the mechanical lithosphere (isotherm 700 $750^{\circ} \mathrm{C}$ ). In contrast, a crust-mantle decoupling could reduce the total strength of the lithosphere [McNutt et al., 1988; Burov and Diament, 1992, 1995]. This reduction of $T_{e}$ is also related to the crustal thickness and the thermal age of the lithosphere.

Our results point out that $T_{e}$ is low beneath active volcanic and rift areas (14-20 km) and is rather high in cratonic areas $(\sim 40 \mathrm{~km})$. We can generalize from our results and emphasize that in continental areas there is obviously a relationship between $T_{e}$, tectonic activity, and the stability of the lithosphere. In other words, heating, rifting, seismic and magmatic activities could weaken the mechanical lithosphere; thus, in areas affected by such processes, one expects relatively low flexural rigidity. No assumption is made here about the age/temperature dependence of $T_{e}$, because of a lack of information on geotherms in the study area. However, the anomalously hot upper mantle beneath the Adamawa uplift and the relatively low $T_{e}$ estimates found in this study suggest that the two parameters (i.e., $T_{e}$ and temperature) are inversely proportional, with higher temperature and volcanism corresponding to lower $T_{e}$ values.

Acknowledgments. We are grateful to ORSTOM (France), IRGM (Cameroon), DMA (USA), ELF (France-Cameroon), and the University of Leeds (UK) for providing the gravity data used in this study. We are indebted to E. B. Burov and Y. Albouy for the many discussions. We also thank M. Zuber, G. Houseman, and K. Gallagher for helpful comments on the manuscript. Y.H.P.D. benefited from a grant of the Département Terre-Océan-Atmosphère of ORSTOM. This study was supported by the Basin Analysis of Africa Project/GETECH (UK) and by the Action Incitative Tomographie de l'INSU (France). IPGP contribution 1365.

\section{References}

Anderson, D. L., Superplumes or supercontinents?, Geology, 22, 3942, 1994.

Baudin, P., C. Coulon, M. Maluski, M. Popoff, and P. Vidal, Dating, geochemistry and geodynamic significance of the Mesozoic magmatism of the Benue trough, Nigeria, Terra Abstr., 3, 500, 1991.

Bechtel, T. D. D., D. W. Forsyth, and C. Swain, Mechanism of isostatic compensation in the vicinity of the East African rift, Kenya, Geophys. J. R. Astron. Soc., 90, 445-465, 1987. 
Bendat, J. S., and A. G. Piersol, Engineering applications of correlation and spectral analysis, John Wiley, New York, 1980.

Benkhelil, J., and R. Guiraud, La Bénoué (Nigéria): Une chaîne intracontinentale de style atlasique, C. R. Acad. Sci., Sér. D, 290, 1517-1520, 1980.

Black, R., J. Lameyre, and B. Bonin, The structural setting of alkaline complexes, J. Afr. Earth Sci., 3, 5-16, 1985.

Bonvalot, S., Mesures gravimétriques en Guinée et Sierra-Leone, Modélisation structurale et étude du comportement mécanique de la lithosphère: Etude d'une chaine péricratonique, d'un bombement intraplaque et de marges transformantes, thèse doctorat, Univ. Paris VI, 1990.

Browne, S. E., and J.D. Fairhead, Gravity study of the Central African Rift System: a model of continental disruption, 1, The Ngaoundere and Abu Gabra Rifts, Tectonophysics, 94, 187-203, 1983.

Burke, K. C., The Chad basin: An active intra-continental basin, Tectonophysics, 36, 197-206, 1976.

Burov, E. B., and M. Diament, Flexure of the continental lithosphere with multilayered rheology, Geophys. J. Int., 109, 449-468, 1992.

Burov, E. B., and M. Diament, The effective elastic thickness $\left(T_{e}\right)$ of continental lithosphere: What does it really mean?, J. Geophys. Res., 100, 3905-3927, 1995.

Chakraborty, K., and B. N. P. Agarwal, Mapping of crustal discontinuities by wavelength filtering of the gravity field, Geophys. Prospect., 41, 801-822, 1992.

Cianciara, B., and H. Marcak, Interpretation of gravity anomalies by means of local power spectra, Geophys. Prospect., 24, 273-286, 1976.

Collignon, F., Gravimétrie de reconnaissance du Cameroun, 37 pp., ORSTOM, Paris, 1968.

Cornacchia, M., and R. Dars, Un trait structural majeur du continent africain. Les linéaments centrafricains du Cameroun au Golfe d'Aden, Bull. Soc. Geol. Fr., 25, 101-109, 1983.

Cratchley, C. R., P. Louis, and D. E. Ajakaiye, Geophysical and geological evidence for the Benue-Chad basin Cretaceous rift valley system and its tectonic implications, J. Afr. Earth Sci., 2(2), 141-150, 1984.

De Almeida, F. M., and R. Black, Comparaison structurale entre le Nord-est du Brésil et l'Ouest Africain, paper presented at Symposium on Continental Drift, Montevidéo, Uruguay, 1967.

Déruelle, B., C. Moreau, C. Nkoumbou, R. Kambou, J. Lissom, E. Njonfang, R. T. Ghogomu, and A. Nono, The Cameroon Line: A review, in Magmatism in Extensional Structural Settings. The Phanerozoic African Plate, edited by A. B. Kampunzu and R. T. Lubala, pp. 274-327, Springer-Verlag, New York, 1991.

Diament, M., and M. G. Kogan, Long wavelength gravity anomalies and the deep thermal structure of the Baikal rift, Geophys. Res. Lett., 17(11), 1977-1980, 1990.

Dimitriadis, K., G. A. Tselentis, and K. Thanassoulas, A basic program for 2-D spectral analysis of gravity data and source depth estimation, Comp. and Geosci. 13(5), 549-460, 1987.

Dorbath, C., L. Dorbath, J. D. Fairhead, and G. W. Stuart, A teleseimic delay time study across the Central African Shear Zone in the Adamawa region of Cameroon, West Africa, Geophys. J. R. Astron. Soc., 86, 751-766, 1986.

Dumont, J. F., Identification par télédétection de l'accident de la Sanaga (Cameroun): Sa position dans le contexte des grands accidents d'Afrique Centrale et de la limite nord du craton Congolais, Géodynamique , 2(1), 13-19, 1986.

Ebinger, C. J., T. D. Bechtel, D. W. Forsyth, and C. O. Bowin, Effective elastic plate thickness beneath the East African and Afar plateaus and dynamic compensation of the uplifts, J. Geophys. Res., 94, 2883-2901, 1989.

El Abbass, T., C. Jallouli, Y. Albouy, and M. Diament, A comparison of surface fitting algorithms for geophysical data, Terra Nova, 2 , 467-475, 1990.

Fairhead, J. D., and C. S. Okereke, A regional gravity study of the West African rift system in Nigeria and Cameroon and its tectonic interpretation, Tectonophysics, 143, 141-159, 1987.

Fairhead, J. D., and C. S. Okereke, Depths to major density contrasts beneath the West-African rift system in Nigeria and Cameroon based on the spectral analysis of gravity data, J. Afr. Earth Sci., 7, 769-777, 1988.

Fairhead, J. D., and C. S. Okereke, Crustal thinning and extension beneath the Benue trough based on gravity studies, J. Afr. Earth Sci., 11, 329-335, 1990.
Fitton, J. G., and H. M. Dunlop, The Cameroon Line, West Africa and its bearing on the origin of oceanic and continental basalts, Earth Planet. Sci. Lett., 72, 23-38, 1985.

Forsyth, D. W., Subsurface loading and estimate of flexural rigidity of continental lithosphere, J. Geophys. Res., 90, 12,623-12,632, 1985.

Freeth, S. J., How many rifts are there in West Africa?, Earth Planet. Sci. Lett., 67, 219-227, 1984.

Genik, G. J., Regional framework, structural and petroleum aspects of rift basins in Niger, Chad and Central African Republic (C.A.R.), Tectonophysics, 213, 169-185, 1992.

Girod, M., J. M. Dautria, E. Ball, and D. Soba, Pétrologie- Estimation de la profondeur du Moho sous le massif volcanique de l'Adamaoua (Cameroun), à partir de l'étude des enclaves de lherzolite, C. $R$. Acad. Sci. Paris, Ser. II, 298, 699-704, 1984.

Guiraud, R., and J. C. Maurin, Early Cretàceous rifts of western and central Africa, Tectonophysics, 213, 153-168, 1992.

Hadiouche, O., and N. Jobert, Geophysical distribution of surfacewave velocities and 3-D upper-mantle structure in Africa, Geophys. J. Int., 95, 87-109, 1988.

Halliday, A. N., J. P. Davidson, P. Holden, C. Dewolf, D.-C. Lee, and J.-G. Fitton, Trace element fractionation in plumes and the origin of HIMU mantle beneath the Cameroon Volcanic Line, Nature, 347, 523-528, 1990.

Hammer, S., Terrain corrections for gravimeter stations, Geophysics, 4 (3), 184-194, 1939.

Hopper, J. R., J. C. Mutter, R. L. Larson, C. Z. Mutter, C. Z., and Northwest Australia Study Group, Magmatism and rift margin evolution: Evidence from northwest Australia, Geology, 22, 853857, 1992

Inoue, $H$., A least-squares smooth fitting for irregularly spaced data: Finite element approach using the cubic B-spline basis, Geophysics, 51(11), 2051-2060, 1986.

Jorgensen, G. J., and W. Bosworth, Gravity modelling in the Central African Rift System, Sudan: Rift geometries and tectonic significance, J. Afr. Earth Sci., 8, 283-306, 1989.

Karche, J. P., and M. Vachette, Migration des complexes subvolcaniques à structure annulaire du Niger, C. R. Acad. Sci., 282, 2033-2036, 1976

Lesquer, A., A. Bourmatte, and Dautria, Deep structure of the Hoggar domal uplift (central Sahara, South Algeria) from gravity, thermal and petrological data, Tectonophysics, 152, 71-87, 1988.

Louis, P., Contribution géophysique à la connaissance du bassin du Lac Tchad, Mem. ORSTOM, 42, 311 pp., 1970.

Martin, A. K., C. J. H. Hartnady, and S. W. Goodlad, A revised fit of South America and south central Africa, Earth Planet. Sci. Lett., 54, 293-305, 1981.

McNutt, M. K., M. Diament, and M. G. Kogan, Variations of elastic plate thickness at continental thrust belts, J. Geophys. Res., 93, 8825-8838, 1988.

Moreau, C., J. M. Regnoult, B. Déruelle, and B. Robineau, A new tectonic model for the Cameroon Line, Central Africa, Tectonophysics, 139, 317-334, 1987.

Mourgues, P., Etude par les ondes $\mathbf{P}$ de la structure du manteau supérieur de l'Afrique Centrale: Un cas de bouclier affecté par un rift intraplaque, thèse doctorat, 267 pp., Univ. Louis Pasteur, Strasbourg, 1983.

Munk, W., and D. E. Cartwright, Tidal spectroscopy and prediction, Philos. Trans. R. Soc. London A, 259, 553-589, 1966.

Ngako, V., P. Jegouzo, and J. P. Nzenti, Le cisaillement center Camerounais. Rôle structural et géodynamique dans l'orogénèse panafricaine, C. R. Acad. Sci., Ser. II, 313, 457-463, 1991.

Ngangom, E., Etude tectonique du fossé de la Mbéré et du Djerem, Sud Adamaoua, in Rifts et Fossés Anciens, (edited by M. Popoff and J. J. Tiercelin), Bull. Centr. Rech. Explor. Produc. Elf-Aquitaine Pau, 7, 339-347, 1983.

Njilah, I. K., Geochemistry and petrogenesis of Tertiary-Quaternary volcanic rocks from Oku-Ndu area, NW Cameroon, Ph.D. thesis, 345 pp., Univ. of Leeds, Leeds, England, 1991.

Nnange, J. M., A macroseismic study of the Tibati earthquake of January 26, 1987, internal report, Inst. de Rech. Geol. et Minière, Yaoundé, Cameroon, 1988.

Nnange, J. M., The crustal structure of the Cameroon volcanic line and the Foumban shear zone based on gravity and aeromagnetic data, Ph.D. thesis, 242pp., Univ. of Leeds, Leeds, England, 1991.

Nnange, J. M., D. Soba, J. D. Fairhead, and G. W. Stuart, Earthquake activity in Cameroon during 1983, Rev. Sci. Tech., Sér. Sci. Terre, $1 / 2,45-53,1985$. 
Okereke, C. S., Contrasting modes of rifting: The Benue trough and the Cameroon volcanic line, West Africa, Tectonics, 7, 775-784, 1988.

Pal, P. C., K. K. Khuruna, and P. Unnikrishnan, Two examples of the spectral approach to source depth estimation in gravity and magnetics, Pure Appl. Geophys., 117, 772-783, 1979.

Parker, R. L., and M. K. McNutt, Statistics for the one-norm misfit measure, J. Geophys. Res., 85, 4429-4430, 1980.

Pilkington, M., Mapping elastic lithospheric thickness variations in Canada, Tectonophysics, 190, 283-297, 1991.

Plomerova, J., V. Babuska, C. Dorbath, L. Dorbath, and R. J. Lillie, Deep lithospheric structure across the Central African Shear Zone in Cameroon, Geophys. J. Int. , 115, 381-390, 1993.

Popoff, M., Du Gondwana à l'Atlantique Sud: Les connexions du fossé de la Benoué avec les bassins du Nord-Est brésilien jusqu'à l'ouverture du golfe de Guinée au Crétacé inférieur, J. Afr. Earth Sci., 7, 409-431, 1988.

Poudjom Djomani, Y. H., Apport de la gravimétrie à la connaissance de la lithosphere continentale et implications géodynamiques: Etude d'un bombement intraplaque: Ie massif de l'Adamaoua (Cameroun), thèse doctorat, 294 pp., Univ. Paris Sud, Orsay, France, 1993.

Poudjom Djomani, Y. H., M. Diament, and Y. Albouy, Mechanical behaviour of the lithosphere beneath the Adamawa uplift (Cameroon, West Africa) based on gravity data, J. Afr. Earth Sci., 15, 81-90, 1992.

Poudjom Djomani, Y. H., C. Ebinger, M. Diament, and Y. Albouy, A gravity study of Cameroon (Central Africa) and discussion of the origin of the Adamawa uplift, Terra Abstr., 5, $110,1993$.

Rahaman, M. A., O. Van Breemen, P. Bowden, and J. N. Bennett, Age migrations of anorogenic ring complexes in Northern Nigeria, $J$. Geol., 92, 173-184, 1984.

Regan, R. D. and W. J. Hinze, The effect of finite data length in the spectral analysis of ideal gravity anomalies, Geophysics, 4I(1), 44-55, 1976.

Singleton, R. C., An algorithm for computing the mixed radix fast Fourier transform, IEEE Trans. Audio Electroacoust., Au-17, 93103, 1969.

Soller, D. R., D. R. Richard, and D. B. Richard, A new global crustal thickness map, Tectonics, 1, 145-149, 1982.
Spector, A., and F. S. Grant, Statistical models for interpreting aeromagnetic data, Geophysics, 35, 293-302, 1970.

Stuart, G. W., J. D. Fairhead, L. Dorbath, and C. Dorbath, A seismic refraction study of the crustal structure associated with the Adamawa plateau and Garoua rift, Cameroon, West Africa, Geophys. J. R. Astron. Soc., 81, 1-12, 1985.

Syberg, F. J. R., A Fourier method for the regional-residual problem of potential fields, Geophys. Prospect., 20, 47-75, 1972.

Tabod, C. T., Seismological studies of the Cameroon volcanic line in West Africa, Ph.D. thesis, 278 pp., Univ. of Leeds, Leeds, England, 1991.

Tabod, C. T., J. D. Fairhead, G. W. Stuart, B. Ateba, and N. Ntepe, Seismicity of the Cameroon volcanic line, 1982-1990, Tectonophysics, 212, 303-320, 1992.

Vail, J. R., Ring complexes and related rocks in Africa, J. Afr. Earth Sci., 8, 19-40, 1989.

Wilson, M., and R. Guiraud, Magmatism and rifting in western and central Africa, from Late Jurassic to Recent times, Tectonophysics, $213,203-225,1992$.

Zuber, M. T., T. D. Bechtel, and D. W. Forsyth, Effective Elastic thickness of the lithosphere and mechanisms of isostatic compensation in Australia, J. Geophys. Res., 94, 9353-9367, 1989.

M. Diament, Institut de Physique du Globe de Paris, Laboratoire de Gravimétrie et Géodynamique (J.E. 335), Institut de Physique du Globe, Case 89, 4 place Jussieu, 75252 Paris Cedex 05, France. (emai1: diament@ipgp.jussieu.fr)

C. J. Ebinger, J. D. Fairhead, and Y. H.Poudjom Djomani, Department of Earth Sciences, University of Leeds, Leeds LS2 9JT, England. (e-mail: cindy@earth.leeds.ac.uk; jdf@getech.leeds.ac.uk; yvette@earth.leeds.ac.uk)

J. M. Nnange, Institut de Recherche Géologique et Minières, P.O. Box 4110 Yaoundé, Cameroon.

(Received June 23, 1994; revised March 29, 1995; accepted April 4, 1995.) 